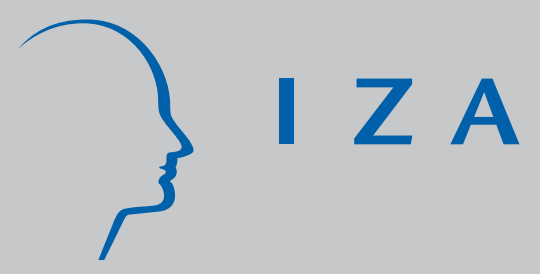

IZA DP No. 1902

The Impact of Labor Markets on the Transmission of Monetary Policy in an Estimated DSGE Model

Kai Christoffel

Keith Kuester

Tobias Linzert

December 2005 


\title{
The Impact of Labor Markets on the Transmission of Monetary Policy in an Estimated DSGE Model
}

\author{
Kai Christoffel \\ European Central Bank \\ Keith Kuester \\ Goethe University, Frankfurt \\ Tobias Linzert \\ European Central Bank \\ and IZA Bonn
}

\section{Discussion Paper No. 1902 \\ December 2005}

\author{
IZA \\ P.O. Box 7240 \\ 53072 Bonn \\ Germany \\ Phone: +49-228-3894-0 \\ Fax: +49-228-3894-180 \\ Email: iza@iza.org
}

\begin{abstract}
Any opinions expressed here are those of the author(s) and not those of the institute. Research disseminated by IZA may include views on policy, but the institute itself takes no institutional policy positions.

The Institute for the Study of Labor (IZA) in Bonn is a local and virtual international research center and a place of communication between science, politics and business. IZA is an independent nonprofit company supported by Deutsche Post World Net. The center is associated with the University of Bonn and offers a stimulating research environment through its research networks, research support, and visitors and doctoral programs. IZA engages in (i) original and internationally competitive research in all fields of labor economics, (ii) development of policy concepts, and (iii) dissemination of research results and concepts to the interested public.
\end{abstract}

IZA Discussion Papers often represent preliminary work and are circulated to encourage discussion. Citation of such a paper should account for its provisional character. A revised version may be available directly from the author. 
IZA Discussion Paper No. 1902

December 2005

\section{ABSTRACT}

\section{The Impact of Labor Markets on the Transmission of Monetary Policy in an Estimated DSGE Model*}

Real wages are a key determinant of marginal costs. The latter themselves are a driving force of inflation. We ask how wages and labor market shocks feed into the inflation process. We model search and matching frictions in the labour market in an otherwise standard NewKeynesian closed economy DSGE model. We estimate the model using Bayesian techniques for German data from the mid 70s to present. In our framework, we find that labor market structure is important for the evolution of the business cycle, and for monetary policy in particular. Yet labor market shocks are not important information for the conduct of stabilization policy.

JEL Classification: E52, E58, J64

Keywords: labor market, wage rigidity, bargaining, Bayesian estimation

Corresponding author:

Keith Kuester

Goethe University

Mertonstrasse 17, PB 94

60054 Frankfurt am Main

Germany

Email: kuester@wiwi.uni-frankfurt.de

\footnotetext{
"We thank participants of the Bundesbank workshop on "Dynamic Macroeconomic Modelling" in Frankfurt, September $20^{\text {th }}, 2005$. Especially, we are indebted to Olivier Pierrard for his insightful discussion of the paper and to Michael Krause and Thomas Lubik for helpful comments. We are also grateful for comments by and discussions with Philip Jung and Ernest Pytlarczyk. Kuester would like to thank the Bundesbank for its hospitality and financial support during part of this research project. The views expressed in this paper are those of the authors. The opinions expressed do not necessarily reflect the views of the European Central Bank or the Bundesbank.
} 


\section{Introduction}

Labor is an important determinant of economic activity. It is well understood that labor markets deviate from spot competitive markets. Especially European labor markets are characterized by high and prolonged unemployment, workers are protected by labor legislation and wages are far from being flexible. Understanding the labor market might be crucial for understanding business cycle fluctuations in general and monetary policy transmission in particular.

In this paper we estimate a New Keynesian business cycle model incorporating labor market frictions and wage rigidities using a Bayesian estimation approach. We estimate the model on German data, since it covers a large area of homogenous labor market settings and displays several types of rigidities characteristic of European labor markets. We explore the question how the labor market regime affects the transmission process of monetary policy. In particular, we will analyze the impact of a monetary policy shock for different degrees of real wage rigidity and overall labor market flexibility. Moreover, we will investigate how labor market shocks affect business cycle dynamics. The full information Bayesian estimation allows us to analyze the role of labor market rigidities and to explicitly account for the relative importance of economic shocks in our model.

The by now traditional New Keynesian model of business cycle fluctuations generally abstracts from modelling a fully-fledged labor market. However, the degree of rigidities in wages is frequently found to play a key role in models employing the Calvo price and wage setting framework. Christiano, Eichenbaum, and Evans (2005), for instance, show that wage contracts are the key nominal friction in their model generating inertia in inflation as well as persistence in output. While these models incorporate various types of nominal and real rigidities they still maintain the assumption of a fully flexible labor market. More specifically, the models abstract from frictions stemming from the presence of unemployment, the relative adjustments in employment and hours and real wage rigidities. 
We embed the labor market matching model as laid out in Trigari (2004) into the modelling approach of Smets and Wouters (2003). ${ }^{1}$ In contrast to the standard New Keynesian business cycle model, our model includes the following Non-Walrasian labor market features: first, matching frictions generate unemployment in equilibrium. Second, adjustments can be made in both employment and in hours worked. Third, workers and firms bargain over wages in a collective wage bargaining manner depending on respective bargaining strength and reservation wages. And fourth, we constrain the adjustments via wages by introducing a wage rigidity. ${ }^{2}$

A specific focus of the paper is to investigate how the labor market is linked to monetary policy. There are several reasons why the labor market may be important for monetary policy.

First, adjustments in the labor market, e.g. the flows in and out of employment or the dynamics of real wages may affect the overall transmission of monetary policy to inflation. Labor costs are an important determinant of firms' marginal cost. Firms' marginal cost in turn determine firms' price setting and are driving aggregate inflation dynamics. The cost of labor input is influenced, for example, by the degree of nominal wage rigidity, the speed with which idle labor resources, i.e. the unemployed, can be put to work and the cost of searching for labor. We will analyze the impact of our structural labor market specification on the propagation of economic shocks. In particular, we will in depth investigate the transmission of a monetary policy shock under different degrees of wage rigidity and labor market flexibility.

Second, shocks in the labor market may directly affect nominal and real economic variables. For example, a period specific change in hiring costs can significantly affect the wage bargaining process that in turn pushes inflation in one or the other direction. Smets and Wouters (2003) estimate a DSGE model with a set of structural shocks

\footnotetext{
1 Trigari (2004) incorporates a labor market matching model à la Mortensen and Pissarides (1994) into a DSGE model.

2 The introduction of a wage rigidity into the matching framework follows the intuition of Hall (2005) and Shimer (2005).
} 
such as, e.g. shocks to productivity or preferences. Advancing on their model, we additionally incorporate a labor market institution shock. We will analyze whether and how shocks in the labor market, that affect firms' profits and hence their vacancy posting, will affect the evolution of output and inflation. If indeed they do, labor market shocks would deliver additional information for the central bank for stabilizing output and for containing inflation.

Our main results are summarized as follows. First, the underlying structure of the labor market significantly affects the transmission process of monetary policy. In particular, we can show that the degree of real wage rigidity is crucial in determining the dynamics of inflation after a monetary policy shock. The impact of the labor market structure on aggregate consumption is, however, rather limited. Second, labor market shocks are not decisive for the dynamics of output and inflation in our model. Therefore, monetary policy need not react to labor market specific shocks via its interest rate rule.

The rest of the paper is organized. Section 2 lays out the theoretical model that we will estimate. Section 3 shows the Bayesian calibration and priors for the estimation. Estimation results are given in Section 4 while Section 5 discusses the results in terms of the specific interrelation of labor markets and monetary policy transmission. Section 6 offers some conclusions and outlook for further research. 


\section{The Model}

Our analysis builds on a standard New-Keynesian framework augmented by Mortensen and Pissarides (1994) type matching frictions in the labor market but with exogenous separation as in Trigari (2004). ${ }^{3}$ We advance on her model by extending it by a number of structural shocks in order to describe the aggregate behaviour of the economy and by allowing for real wage rigidity. As is common in the literature, we focus on a cashless limit economy; cp. Smets and Wouters (2003) and large parts of Woodford (2003).

\subsection{Households' Consumption and Saving Decision}

One-worker households are uniformly distributed on the unit interval and indexed by $i \in(0,1)$. They are infinitely lived and seek to maximize expected lifetime utility by deciding on the level (and intertemporal distribution) of consumption of a bundle of consumption goods, $C_{t}(i)$, and by holding pure discount bonds $B_{t}(i)$,

$$
\max _{\left\{C_{t}(i), B_{t}(i)\right\}} E_{t}\left\{\sum_{j=0}^{\infty} \beta^{j}\left\{\epsilon_{t+j}^{\text {pref }} U\left(C_{t+j}(i), C_{t+j-1}\right)-g\left(h_{t+j}(i)\right)\right\}\right\}, \beta \in(0,1)
$$

subject to the budget constraint

$$
C_{t}(i)+\frac{B_{t}(i)}{P_{t} R_{t}}=D_{t}+B_{t-1}(i) / P_{t}
$$

Here $R_{t}$, which is assumed to be the monetary authority's policy instrument, denotes the gross nominal return on the bond. Households own the firms in the economy, hence are entitled to their profits. Following much of the literature, we assume that households pool their income. There is perfect consumption risk sharing. $D_{t}$ denotes the income each household receives from (a) labor market activity, (b) profits of firms

\footnotetext{
${ }^{3}$ Separation rates in Germany are constant over the business cycle (see Bachmann, 2005, and the references therein) - we therefore assume that each period a constant fraction of firm-worker relationships splits up for reasons exogenous to the state of the economy. A similar argument for the U.S. is made by Hall (2005).
} 
and (c) government transfers, such as unemployment benefits minus lump-sum taxation and payments under the income insurance scheme. Above, $\epsilon_{t}^{\text {pref }}$ is an i.i.d. shock to the intertemporal elasticity of substitution of consumption. We refer to this shock as the demand shock.

Let $C_{t-1}$ be the aggregate consumption level in period $t-1$. We assume that individual consumption is subject to external habit persistence, indexed by parameter $h_{c} \in[0,1)$,

$$
U\left(C_{t}(i), C_{t-1}\right)=\frac{\left(C_{t}(i)-h_{c} C_{t-1}\right)^{1-\sigma}}{1-\sigma}
$$

As in Abel (1990) households therefore are concerned with "catching up with the Joneses". 4

The first-order conditions can be summarized in the standard Euler equation

$$
\lambda_{t}=\beta E_{t}\left\{\lambda_{t+1} \frac{R_{t}}{\Pi_{t+1}}\right\}
$$

where $\lambda_{t}=\epsilon_{t}^{p r e f}\left(C_{t}-h_{c} C_{t-1}\right)^{-\sigma}$ marks marginal utility of consumption and $\Pi_{t}$ is the gross inflation rate. ${ }^{5}$

To complete the description of preferences, disutility of work is characterized by

$$
g\left(h_{t}(i)\right)=\kappa_{h, t} \frac{h_{t}(i)^{1+\phi}}{1+\phi}, \phi>0, \kappa_{h, t}>0
$$

\footnotetext{
4 The specification of the utility function is standard, see e.g. Smets and Wouters (2003). However, strictly speaking, if the economy is not close to steady state, neither is it guaranteed that marginal utility of consumption is positive nor that utility is real. A minor modification of the utility function that yields the same first-order approximation to the Euler equation apart from the definition of the shock process but does not suffer from above problems is $U\left(C_{t}(i), C_{t-1}\right)=\frac{1}{1-\sigma} C_{t}(i)^{1-\sigma} C_{t-1}^{\sigma h}$. In this case $\lambda_{t}=\epsilon_{t}^{\text {pref }} C_{t}^{-\sigma} C_{t-1}^{\sigma h}$. A similar specification can be found in Fuhrer (2000). Boldrin, Christiano, and Fisher (2001) argue that the ability of standard general equilibrium models to fit the equity premium and other asset market statistics is greatly improved by the presence of external habit formation in preferences. For advantages and disadvantages of the internal vs. external habit specifications see for instance the extensive discussion in Campbell, Lo, and MacKinlay (1997, chap. 8.4).

${ }^{5}$ Due to consumption insurance, all households in equilibrium will have the same consumption levels. We therefore suppress index $i$.
} 
Here, $\kappa_{h, t}$ denotes a serially correlated shock to the disutility of work:

$$
\log \left(\kappa_{h, t}\right)=\log \left(\overline{\kappa_{h}}\right)\left(1-\rho_{\kappa_{h}}\right)+\rho_{\kappa_{h}} \log \left(\kappa_{h, t-1}\right)+\mu_{t}^{\kappa_{h}}, 0<\rho_{\kappa_{h}}<1,
$$

where $\mu_{t}^{\kappa_{h}}$ is an i.i.d. innovation.

\subsection{Production}

The recent vintages of New Keynesian models assume that prices are costly to adjust but that given this cost structure firms behave optimally. This leads to different firms in the economy having different prices and hence facing different demand. Following the literature (see e.g. Trigari, 2004), we therefore part the markup pricing decision from the labor demand decision.

There are three types of firms. Intermediate good producing firms need to find a worker in order to produce. It is here that labor market matching and bargaining occurs. Once a firm and a worker have met, wages are negotiated and firms take hours worked as their sole input to production. Intermediate goods are homogenous. The goods are sold to a wholesale sector in a perfectly competitive market at real price $x_{t}$. Firms in the wholesale sector take only intermediate goods as input, and differentiate those. Subject to price setting impediments à la Calvo (1983), they sell to a final retail sector under monopolistic competition. Retailers bundle differentiated goods to a consumption basket $C_{t}$ and under perfect competition sell this final good to consumers at price $P_{t}$. We next turn to a detailed description of the respective sectors.

\subsubsection{Intermediate Goods Producers}

There is an infinite number of potential intermediate goods producers. Firms in production are symmetric one-worker firms. Before entering production, firms currently 
out of production have to decide whether they want to incur a real search cost/vacancy posting cost to stand a chance of recruiting a worker. This cost is labeled $\kappa_{t} / \lambda_{t}>0{ }^{6}$ We assume that vacancy posting costs follow an autoregressive process

$$
\log \left(\kappa_{t}\right)=\log (\bar{\kappa})\left(1-\rho_{\kappa}\right)+\rho_{\kappa} \log \left(\kappa_{t-1}\right)+\mu_{t}^{\kappa}, 0<\rho_{\kappa}<1,
$$

where $\mu_{t}^{\kappa}$ is an i.i.d. innovation. Let $V_{t}$ be the market value of a prototypical firm out-of-production in $t$ and $J_{t}$ the value of a firm in $t$ that already found a worker prior to period $t,{ }^{7}$ then

$$
V_{t}=-\frac{\kappa_{t}}{\lambda_{t}}+E_{t}\left\{\beta_{t, t+1} q_{t}(1-\rho) J_{t+1}\right\}
$$

where $q_{t}$ denotes the probability of finding a worker in $t, \rho$ is the constant probability that a match is severed for an exogenous reason prior to production in $t+1$ and $\beta_{t, t+j}:=\beta^{j} \frac{\lambda_{t+j}}{\lambda_{t}}$ denotes the equilibrium pricing kernel. $q_{t}$ is the probability that a searching firm finds a worker. ${ }^{8}$

Labor (hours worked) is the only factor of production. Each firm $j$ in the intermediate good sector has the same production technology with decreasing returns to labor

$$
y_{t}^{I}(j)=z_{t} h_{t}(j)^{\alpha}, \alpha \in(0,1) .
$$

Here $y_{t}^{I}(j)$ marks the amount of the homogenous intermediate good produced by firm $j$ and $z_{t}$ marks the economy wide level of productivity. Intermediate goods producers sell their product in a competitive market at real (in terms of the final good) price $x_{t}$. Labor is paid the real hourly wage rate $w_{t}$. So the value as of period $t$ of a firm, the

\footnotetext{
${ }^{6}$ Since marginal utility of consumption, $\lambda_{t}$ tends to be low in booms and high in recessions, this specification implies procyclical real vacancy posting costs. This c.p. dampens labor market activity.

${ }^{7}$ Wherever it is clear from the context that variables refer to a specific firm/worker match, as it should be here, we do not index variables by $j$.

${ }^{8}$ In principle, in period $t$ firms that found a worker prior to period $t$ decide whether to produce or not to produce. Our assumption that separation is exogenous means we abstract from such considerations. However, we retain the point of no production as our threat point in the wage bargaining process. Implicitly therefore we assume that in equilibrium the bargaining set will always be non-empty.
} 
worker-match of which is not severed prior to production, is given by

$$
J_{t}=\psi_{t}+E_{t}\left\{\beta_{t, t+1}\left[(1-\rho) J_{t+1}+\rho V_{t+1}\right]\right\},
$$

where $\psi_{t}$ is the firm's real per period profit.

Vacancy Posting. We assume that there is free entry into production apart from the sunk vacancy posting cost. This insures that ex ante (pre-production) profits are driven to zero in equilibrium, $V_{t}=0$. Together with (6) and (8) this implies the vacancy posting condition

$$
\frac{\kappa_{t}}{\lambda_{t}}=q_{t} E_{t}\left\{\beta_{t, t+1}(1-\rho)\left[\psi_{t+1}+\frac{\kappa_{t+1}}{\lambda_{t+1} q_{t+1}}\right]\right\} .
$$

Iterating equation (9) forward shows that real vacancy posting costs in equilibrium equal the discounted expected profit of the firm over the life-time of a match.

Matching. We assume a standard Mortensen and Pissarides (1994) type matching market. Let $u_{t}$ be the fraction of workers (households) searching for employment during period $t$, let $v_{t}$ be the number of vacancies posted in period $t$ as a fraction of the labor force. Firms and workers meet randomly. In each period the number of new matches is assumed to be given by the following constant returns to scale matching function

$$
m_{t}=\sigma_{m} u_{t}^{\sigma_{2}} v_{t}^{1-\sigma_{2}}, \sigma_{2} \in(0,1)
$$

$\sigma_{m}>0$ can be understood as the efficiency of matching, which is the rate at which firms and workers meet. $\sigma_{2}$ governs the relative weight the pool of searching workers and firms, respectively, receive in the matching process. We define labor market tightness (from the view point of a firm) as

$$
\theta_{t}:=\frac{v_{t}}{u_{t}}
$$


The probability that a vacant job will be filled,

$$
q_{t}:=\frac{m_{t}}{v_{t}}=\sigma_{m} \theta_{t}^{-\sigma_{2}}
$$

is falling in market tightness, showing the congestion externality of new vacancies. The probability that a searching worker finds a job,

$$
s_{t}:=\frac{m_{t}}{u_{t}}=\sigma_{m} \theta_{t}^{1-\sigma_{2}}
$$

in turn is increasing in market tightness. Each new searcher decreases market tightness and therefore means a negative labor market tightness externality to other workers searching for employment.

Wage Bargaining Preliminaries. Firms and workers bargain only over wages, taking the firm's labor-demand function as given ("Right-to-manage"). Christoffel and Linzert (2005) demonstrate that in a right-to-manage wage bargaining framework wage persistence may contribute to explain a large part of the observed inflation persistence. This channel is missing under the more usual assumption of an efficient bargaining model. We turn to describe each party's surplus from staying matched, which is an integral component of each side's bargaining position. A firm which stays in production receives a period profit $\psi_{t}$ in $t$. With probability $1-\rho$ the current match will not be severed at the beginning of the next period. The firm's surplus therefore is

$$
J_{t}-V_{t}=\psi_{t}+E_{t}\left\{\beta_{t, t+1}(1-\rho)\left(J_{t+1}-V_{t+1}\right)\right\} .
$$

By a similar reasoning, the value of a worker who is not employed but searching during $t$ is $^{9}$

$$
U_{t}=b+E_{t}\left\{\beta_{t, t+1}\left[s_{t}(1-\rho) W_{t+1}+\left(1-s_{t}+s_{t} \rho\right) U_{t+1}\right]\right\},
$$

\footnotetext{
9 This can be derived from first principles by assuming that workers value their labor-market actions in terms of the contribution these actions give to the utility of the family to which they belong and with which they pool their income; see Trigari (2004).
} 
where $b$ stands for the real benefit unemployed workers receive. Taking into account the consumption value of the disutility of work, $\frac{g\left(h_{t}\right)}{\lambda_{t}}$, the value to the worker when employed during period $t$ and not searching is

$$
W_{t}=w_{t} h_{t}-\frac{g\left(h_{t}\right)}{\lambda_{t}}+E_{t}\left\{\beta_{t, t+1}\left[(1-\rho) W_{t+1}+\rho U_{t+1}\right]\right\}
$$

Hence the marginal increase of family utility through an additional family member in employment, the surplus of being in employment in $t$, is given by

$$
W_{t}-U_{t}=w_{t} h_{t}-\frac{g\left(h_{t}\right)}{\lambda_{t}}-b+E_{t}\left\{\beta_{t, t+1}(1-\rho)\left(1-s_{t}\right)\left(W_{t+1}-U_{t+1}\right)\right\}
$$

Real Wage Rigidities. Once matched, each period firms and workers negotiate over the real wage rate subject to adjustment costs which need to be born by the firm. A firm's per period profit is defined as

$$
\psi_{t}(j):=x_{t} y_{t}^{I}(j)-w_{t}(j) h_{t}(j)-\frac{1}{2} \phi_{L}\left(w_{t}(j)-w_{t-1}(j)\right)^{2}
$$

where $w_{t-1}(j)$ is last period's firm-specific wage level (or the average wage level if there is no wage history). ${ }^{10}$ Apart from the direct effect on profits, implicit in this specification is the assumption that the firm perceives real wage changes to bring about additional, unambigously negative effects on profits. For example, real wage decreases may be detrimental to worker motivation. Real wage increases on the other hand cut into wage decrease flexibility in the future. Parameter $\phi_{L}>0$ indexes how strong this motive is. ${ }^{11}$

\footnotetext{
${ }^{10}$ We also experimented with nominal (instead of real) wage adjustment costs and with a Calvo-type staggered wage setting mechanism. Qualitatively, our results are not affected by this choice. See appendices $\mathrm{F}$ and $\mathrm{G}$ for details.

${ }^{11}$ In our model, there is no beneficial motive for fixed wages. In particular, in some circumstances both workers and firms could be made better off by removing the real wage adjustment costs. We leave a more detailed exploration for future research.
} 
With right-to-manage, labor demand is given by the usual competitive optimality condition that the marginal value product of labor, $x_{t} m p l_{t}$, needs to equal the hourly real wage rate.

$$
x_{t} m p l_{t}=w_{t}, \text { where } m p l_{t}:=z_{t} \alpha h_{t}^{\alpha-1} .
$$

Wage Bargaining, Final Ingredients. Firms and workers seek to maximise the overall rents arising from an existing employment relationship. Overall rents from an existing job are distributed according to the bargaining power of workers, $\eta$. Firms and workers, once matched, are assumed to negotiate so as to maximize their weighted joint surplus by a state-contingent choice of the real wage rate:

$$
\max _{\left\{w_{t}(j)\right\}}\left(W_{t}(j)-U_{t}(j)\right)^{\eta}\left(J_{t}(j)-V_{t}(j)\right)^{1-\eta}
$$

The corresponding first order condition is

$$
\eta J_{t}(j) \underbrace{\frac{\partial\left[W_{t}(j)-U_{t}(j)\right]}{\partial w_{t}(j)}}_{:=\delta_{t}^{W, w}(j)}=\underbrace{-\frac{\partial\left[J_{t}(j)\right]}{\partial w_{t}(j)}}_{:=\delta_{t}^{F, w}(j)}(1-\eta)\left(W_{t}(j)-U_{t}(j)\right) .
$$

All firms are identical and each firm resets its wage every period, we can drop individual firm-worker pair indeces. So

$$
\begin{gathered}
\delta_{t}^{F, w}=h_{t}+\phi_{L}\left[\left(w_{t}-w_{t-1}\right)+\beta(1-\rho)\left(w_{t+1 \mid t}-w_{t}\right)\right], \text { and } \\
\delta_{t}^{W, w}=\frac{h_{t}}{\alpha-1}\left\{\alpha-\frac{m r s_{t}}{w_{t}}\right\}, \text { where } m r s_{t}=\frac{\kappa_{h, t} h_{t}^{\phi}}{\lambda_{t}} .
\end{gathered}
$$

Labour Market Flows. Let $n_{t}$ be the measure of employed workers at the beginning of period $t$, before production takes place. A constant fraction $\rho$ of these are layed off just before work starts in $t$ and immediately join the pool of workers searching for a new job. The pool of workers searching during $t$ therefore is:

$$
u_{t}=1-(1-\rho) n_{t} .
$$


The measure of newly matched workers, $m_{t}$, join the pool of employed workers in $t+1$, therefore aggregate employment evolves according to

$$
n_{t}=(1-\rho) n_{t-1}+m_{t-1} .
$$

This closes our description of the labor market and the intermediate good producing sector.

\subsubsection{Wholesale Sector}

Firms in the wholesale sector are distributed on the unit interval and indexed by $i \in(0,1)$. The homogenous intermediate good is the only input to their production. They face a competitive market in this factor of production, paying real price $x_{t}$ per unit, and produce a differentiated good $y_{t}(i)$. Their production function is linear in the intermediate good,

$$
y_{t}(i)=y_{t}^{I}(i),
$$

where $y_{t}^{I}(i)$ denotes wholesale firm $i$ 's demand for the homogeneous intermediate good. The real price of the intermediate good, $x_{t}$, therefore coincides with their marginal cost. The typical firm sells its differentiated output in a monopolistically competitive market at nominal price $p_{t}(i)$. We follow Calvo (1983) in assuming that in each period a random fraction $\varphi \in(0,1)$ of firms cannot update their price. Following Christiano, Eichenbaum, and Evans (2005) and Smets and Wouters (2003), we assume that firms who cannot adjust their prices partially index to the realized inflation rate. The degree of indexation is measured by parameter $\gamma \in(0,1)$.

Wholesale firms face the demand function:

$$
y_{t}(i)=\left(\frac{p_{t}(i)}{P_{t}}\right)^{-\epsilon_{t}^{c p}} y_{t}, \epsilon_{t}^{c p}>1,
$$

where $P_{t}$ is the economy wide price index and $y_{t}$ is an aggregate index demand. The cost-push shock is modelled as a time-varying (own-price) elasticity of demand, $\epsilon_{t}^{c p}$. 
We assume that there are shocks, $\mu_{t}^{c p}$, to the elasticity of demand,

$$
\log \left(\epsilon_{t}^{c p}\right)=\log \left(\bar{\epsilon}^{c p}\right)+\mu_{t}^{c p}
$$

which are i.i.d. over time.

Wholesale firms which are allowed to update their price in period $t$ face the problem of maximizing the value of their enterprise by choosing their sales price $p_{t}(i)$ taking into account the pricing frictions and their demand function:

$$
\max _{p_{t}(i)} E_{t}\left\{\sum_{j=0}^{\infty} \varphi^{j} \beta_{t, t+j}\left[\frac{p_{t}(i)}{P_{t+j}} \prod_{l=0}^{j-1}\left(\Pi_{t+l}^{\gamma_{p}} \bar{\Pi}^{1-\gamma_{p}}\right)-x_{t+j}\right] y_{t+j}(i)\right\}
$$

where $\bar{\Pi}$ is the gross inflation rate in steady state. Their first order condition is:

$$
E_{t}\left\{\sum_{j=0}^{\infty} \varphi_{p}^{j} \beta_{t, t+j}\left[\frac{p_{t}(i)}{P_{t+j}}\left(1-\epsilon_{t+j}^{c p}\right) \prod_{l=0}^{j-1}\left(\Pi_{t+l}^{\gamma_{p}} \bar{\Pi}^{1-\gamma_{p}}\right)+\epsilon_{t+j}^{c p} x_{t+j}\right] y_{t+j}(i)\right\}=0
$$

\subsubsection{Retail Firms}

Retail firms operate in perfectly competitive product markets. They buy differentiated wholesale goods and arrange them into a representative basket, producing the final consumption good $y_{t}$,

$$
y_{t}=\left[\int_{0}^{1} y_{t}(i)^{\frac{\epsilon_{t}^{c p}-1}{\epsilon_{t}^{c p}}} d i\right]^{\frac{\epsilon_{t}^{c p}}{\epsilon_{t}^{c p}-1}} .
$$

The cost-minimizing expenditure to produce one unit of the final consumption good is

$$
P_{t}=\left[\int_{0}^{1} p_{t}(i)^{1-\epsilon_{t}^{c p}} d i\right]^{\frac{1}{1-\epsilon_{t}^{c p}}}
$$

Note that this coincides with the consumer price index.

Closing the representation of production, market clearing in the markets for all goods 
requires that ${ }^{12}$

$$
y_{t}=\left(1-u_{t}\right) y_{t}^{I}=\left(1-u_{t}\right) z_{t} h_{t}^{\alpha}=C_{t}
$$

Before we close the model by a description of monetary policy, we want emphasize the role that our labor market characterization plays in the economy.

\subsection{The Wage-Inflation Channel in the Linearized Model}

In order to arrive at an empirically tractable version of the model, we linearize above equations around a zero-inflation, constant production steady state. While we defer a complete presentation of the linearized model to Appendix A, this section explains the determinants of aggregrate wages and the transmission from wages to inflation in our model. Hats denote percentage deviations from steady state while bars mark steady state values.

The wage equation can be rewritten as

$$
\widehat{w}_{t}=\gamma_{1} \widehat{m r} s_{t}+\gamma_{2}\left(\widehat{\kappa}_{t}-\lambda_{t}+\widehat{\theta}_{t}\right)-\left(\gamma_{2}+\gamma_{3}\right) \widehat{h}_{t}+\xi_{3} \widehat{\chi}_{t}-\xi_{2}\left(\widehat{\chi}_{t+1}-\widehat{\chi}_{t}\right)
$$

Here

$$
\widehat{\chi}_{t}=\widehat{\delta}_{t}^{W, w}-\widehat{\delta}_{t}^{F, w}=\left[\frac{\eta(W-U)_{t} \widehat{+(1-\eta)(J-V)_{t}}}{\partial w_{t}}\right],
$$

and $\hat{\chi}_{t}$ can consequently be interpreted as the approximate effect of a wage increase on total bargaining surplus. This leads to an intuitive interpretation of wage equation (31): Ceteris paribus the real wage rate will be the larger, the larger the worker's marginal rate of substitution of leisure for consumption, i.e. the less willing he is to work an additional instant of time. ${ }^{13}$ In addition, the wage rate will increase with rising real vacancy posting costs $\left(\widehat{\kappa}_{t}-\widehat{\lambda}_{t}\right)$ since these imply larger rents which can

${ }^{12}$ Here we use that wholesale production is linear in intermediate goods and that all intermediate goods firms have the same production level.

13

$$
\xi_{3}=\frac{\bar{\chi}}{1-\frac{\bar{\chi}}{\alpha}}\left(\frac{1}{\alpha}+\frac{\bar{\kappa} \bar{\theta}}{\overline{\lambda w h}}-\frac{\overline{m r s}}{\bar{w}(1+\phi)}-\frac{b}{\overline{w h}}\right)
$$

which is strictly positive in our calibration. All the other parameters in (31) are strictly positive by definition (see Appendix A). 
be extracted from the firm-worker relationship. A similar reasoning is valid for an increase in market tightness, $\theta_{t}$. Decreasing returns to labor mean that additional hours worked will turn ever less productive. The third factor might be interpreted to reflect this feature. The real wage rate will also be the higher the more total surplus increases with an increase in the wage (the $\widehat{\chi}_{t}$ factor). Finally, whenever $\widehat{\chi}_{t+1}-\widehat{\chi}_{t}$ is positive, wage increases in the future have a more positive (less negative) effect on future total surplus than current wage increases have on the current one. This leads firms and workers to defer wage increases to a certain extent and, consequently, has a dampening effect on wages.

As regards the real wage rigidity, the effect of a marginal wage increase on total surplus, $\widehat{\chi}_{t}$, can be decomposed as

$$
\widehat{\chi}_{t}=\frac{\frac{\overline{m r s}}{\bar{w}}}{\frac{\overline{m r s}}{\bar{w}}-\alpha}\left(\widehat{m r s} s_{t}-\widehat{w}_{t}\right)-\phi_{L} \frac{\bar{w}}{\bar{h}}\left[\left(\widehat{w}_{t}-\widehat{w}_{t-1}\right)-\beta(1-\rho)\left(\widehat{w}_{t+1 \mid t}-\widehat{w}_{t}\right)\right] .
$$

Thus the upward pressure on wages is increasing in the gap between the worker's subjective price of work and the market remuneration. In terms of wage rigidity, note that whenever $\phi_{L}>0$, the term $\widehat{w}_{t}-\widehat{w}_{t-1}$ dampens both wage increases and wage reductions. This is done by increasing the total surplus from wage increases whenever there is a tendency to lower the wage rate and by reducing this effect whenever wage increases are imminent.

Wages in our model translate into inflation by increasing the cost of the intermediate good, $x_{t}$, via the intermediate good producer optimality condition

$$
\widehat{x}_{t}=\widehat{w}_{t}-\left(\widehat{z}_{t}+(\alpha-1) \widehat{h}_{t}\right)
$$

Ceteris paribus, an increase in marginal cost through an increase in real wages for the wholesale sector means an increase in inflation via the Phillips curve

$$
\widehat{\pi}_{t}=\frac{\beta}{1+\beta \gamma} E_{t} \widehat{\pi}_{t+1}+\frac{\gamma}{1+\beta \gamma} \widehat{\pi}_{t-1}+\frac{(1-\varphi)(1-\varphi \beta)}{\varphi(1+\beta \gamma)}\left(\widehat{x}_{t}+\widehat{e}_{t}\right) .
$$


All else equal, the impact of wages on marginal cost will be the larger the less pronounced inflation indexation (the closer $\gamma$ to zero) and the larger the fraction of wholesalers allowed to update prices each period (the smaller $\varphi$ ).

\subsection{Monetary Policy}

The monetary authority is assumed to control the nominal one-period risk-free interest rate $R_{t}$. The empirical literature (see, e.g. Clarida, Gali, and Gertler, 1998) finds that simple linearized generalized Taylor-type rules of the type

$$
\widehat{i}_{t}=\rho_{m} \widehat{i}_{t-1}+\left(1-\rho_{m}\right) \gamma_{\pi}\left(\widehat{\pi}_{t+1}-\widehat{\bar{\pi}}_{t}\right)+\left(1-\rho_{m}\right) \gamma_{y} \widehat{y}_{t}
$$

represent a good representation of monetary policy. We allow for a serially correlated inflation target shock

$$
\log \left(\bar{\Pi}_{t}\right)=(1-\rho) \log (\bar{\Pi})+\rho \log \left(\bar{\Pi}_{t-1}\right)+\mu_{t}^{\bar{\Pi}},
$$

where $\mu_{t}^{\bar{\Pi}}$ is an i.i.d. shock. 


\section{Bayesian Calibration}

The literature has recently seen a surge of activity in estimating dynamic stochastic general equilibrium (DSGE) models by means of full information Bayesian techniques; see e.g. Schorfheide (2000), Smets and Wouters (2003), del Negro, Schorfheide, Smets, and Wouters (2004) and Lubik and Schorfheide (2005). The advantage of full information relative to limited information techniques is that the model estimates will provide a complete characterization of the data generating process. In a Bayesian framework, through the prior density, to the modeler's advantage, prior information (derived from other studies, from outside evidence or simply personal judgement) can be brought to bear on the estimation process in a consistent and transparent manner.

The decision of how much weight to place on different sources of prior information in the presence of possible identification problems ultimately depends on the goal of the analysis. We seek to strike a compromise in our calibration, estimating those parameters we think most important for the problem at hand and best identified, and fix the other parameters on the basis of judgement and estimates in the literature.

Fixed Parameters. We now turn to our calibration for the fixed parameters.

- Elasticity of demand: $\bar{\epsilon}^{c p}=11$. Once the elasticity of output with respect to hours worked, $\alpha$, is fixed, the elasticity multiplies only the markup shock. It is therefore indistinguishable from the standard deviation of the markup shock. We fix the own price elasticity of demand to 11, a value implying a markup of $10 \%$ in the wholesale sector as in Trigari (2004).

- Labor share: 0.72 ; implying $\alpha=0.792$. In steady state under right-to-manage the labor share is given by ${ }^{14}$

$$
\text { share }=\frac{\epsilon^{c p}-1}{\epsilon^{c p}} \alpha .
$$

\footnotetext{
14 The labor share is share $=\frac{(1-\rho) n w h}{(1-\rho) n z h^{\alpha}}=x \alpha$, which uses $x \alpha z h^{\alpha-1}=w$ and $y=(1-\rho) n z h^{\alpha}$. With $x=\frac{\epsilon^{c p}-1}{\epsilon^{c p}}$ the desired expression follows.
} 
With an empirical estimate for the labor share and a calibration for $\epsilon^{c p}$, a value for $\alpha$ results. In our closed economy in the absence of "an active government" and capital, the labor share is equal to compensation of employees over total private consumption or, equivalently here, national income. We decide to take the share of wage income in national income as the corresponding measure of the labor share in this model, setting share $=0.72$. Using our mean calibration for $\epsilon^{c p}=11$ this implies $\alpha=0.792$.

- Discount factor: $\beta=0.99$. This is the inverse of the mean ex-post real rate in our sample.

- Labor supply elasticity: $\phi=10$. The elasticity of intertemporal substitution of labor, $1 / \phi$, is small in most microeconomic studies (between 0 and 0.5 ). We follow the lead of Trigari (2004).

- Risk aversion: $\sigma=1$. We decide to use log-utility as is the prior mean in Smets and Wouters (2003).

- Separation rate: $\bar{\rho}=0.08$. This is roughly in line with the evidence reported for instance in Burda and Wyplosz (1994).

- Searching workers: $\bar{u}=0.15$. In the data the mean ratio of employed persons to total labor force is 0.925 . Taking the value of $\bar{\rho}=0.08$ from above, we arrive at a mean fraction of searching workers of $\bar{u}=1-(1-\bar{\rho}) \bar{n}=0.149$.

- Vacancies: $\bar{v}=0.1$. The number of vacancies empirically is hard to observe. We set the steady number of vacancies to $\frac{2}{3}$ the number of searching workers. This ensures that firms rather quickly find new workers, while workers do not.

- $\eta=0.2$. A key determinant of the share of wages in total surplus (yet not in profits) and hence the gap between unemployment benefit and wage income, we use the bargaining power parameter to calibrate the replacement rate $\left(\frac{b}{w h}=0.5\right)$, which seems reasonable for German data. A relatively low bargaining power of workers results. ${ }^{15}$ 
- No serial correlation of the cost-push and the preference (consumption) shock. Wherever possible our prior is to use economic theory to explain the data instead of using serial correlation in shock processes. Abstracting from serial correlation in the cost-push shock is standard in the literature; see e.g. Smets and Wouters (2003). The preference shock in our model strongly drives consumption. Empirically we therefore cannot identify whether the autoregressive pattern in consumption results from an autocorrelated consumption preference shock or from habit persistence in consumption.

Following the guidance of economic theory we let habit persistence explain consumption persistence. On top, this also ensures the typical hump-shaped response of consumption/output to a monetary policy shock.

- Summing up, these values imply a steady-state probability of finding a worker of $\bar{q}=0.74$. The probability of finding a job is $\bar{s}=0.5$. This implies that an average unemployment spell lasts for 2 quarters. Our calibration also implies that structural obstructions to hiring/setting up a firm account for roughly one and a half quarters of production, captured by real vacancy posting $\operatorname{costs} \bar{\kappa} / \overline{\lambda y}=$ $1.5 .{ }^{16}$

Priors for Estimated Parameters. We opt to model priors for almost all parameters as normally distributed with tight enough prior standard deviations and truncated to reflect the support considerations where necessary. ${ }^{17}$ We follow the literature in modelling the standard deviation of innovations as inverse-gamma with fat tails as we lack prior information on those variances. ${ }^{18}$ We assume that all marginal priors are

\footnotetext{
15 Note that Hall (2005) argues that wage persistence is necessary to make profits (and hence vacancies) responsive to the cycle. Key to his argument is also that wages reap a large share of the surplus implying $\eta>>0.2$. Hall, however, applies efficient bargaining.

${ }^{16}$ Note that $\bar{\kappa}_{h}$ is not needed in order to estimate the model and fix the steady state shares. The large value of vacancy posting costs is needed to offset the considerable ex post/per period profits in the intermediate goods sector originating from the decreasing returns to scale in production.

${ }^{17}$ Commonly, beta-distributions are picked for parameters in the unit interval, while gammadistributions are chosen for positive parameters. Appealing as this may be, imposing the betadistribution on parameters also implies strong assumptions on the shape of the prior, not only on its support.
} 
independent.

- Priors for the Taylor rule. As in Taylor's (1993) original suggestion for the U.S., we set the mean $\gamma_{\pi}=1.5$ and the mean $\gamma_{y}=0.5 / 4 .{ }^{19}$ We allow for wide standard deviations of 0.3 for both parameters. Woodford, among others, has repeatedly emphasized that inertia is a property of optimal monetary policy (see e.g. Woodford, 2003). We set a prior mean for the indexation parameter of $\rho_{m}=0.75$ and a standard deviation of 0.05 . Note that these values are very similar to those estimated by Clarida, Gali, and Gertler (1998) on German data. $^{20}$

- Habit persistence: $h_{c}=0.85$. As a value for consumption habit we impose a mean of 0.85 , which is higher than the value of roughly 0.5 commonly found in the literature (cp. e.g. Christiano et al. (2005) and Smets and Wouters (2003)). However, in Smets and Wouters (2003), for instance, the autocorrelation of the preference shock (estimated to be 0.9) is allowed to partly take the burden of explaining the serial correlation of consumption.

- Price stickiness: $\varphi=0.9$. Our prior mean assumes that only $10 \%$ of firms update their prices each quarter, which is the posterior mode estimate of Smets and Wouters (2003) for the euro area. The implication that prices are sticky for an average of 10 quarters is in stark contrast to micro-evidence for the US and the euro area as a whole but may still be tenable for the German economy. See Hoffmann and Kurz-Kim (2004) for evidence. ${ }^{21}$ We impose a standard deviation

${ }^{18}$ Lubik and Schorfheide (2005) follow an interesting approach by using presamples to generate information about specific parameters. For instance, they run a regression $r_{t}=\beta_{0}+\beta_{1} r_{t-1}+$ $\beta_{2} \Delta y_{t-1}+\epsilon_{R, t}$ to generate a prior for the variance of the monetary policy shock.

${ }^{19}$ We deviate from Taylor's (1993) suggestion in modeling the response to inflation as being preemptive, and in modeling interest rate inertia.

20 They use monthly data from 1979 to 1993 and estimate

$$
\widehat{r}_{t}=0.75 \widehat{r}_{t-1}+(1-0.75)\left[1.31 / 4 E_{t}\left\{\widehat{\pi}_{t+4}^{y o y}\right\}+0.25 / 4 \widehat{y}_{t}\right]
$$

where $\widehat{\pi}_{t}^{\text {yoy }}:=\widehat{\pi}_{t}+\widehat{\pi}_{t-1}+\widehat{\pi}_{t-2}+\widehat{\pi}_{t-3}$ marks annual (year-on-year) inflation. The persistence coefficient is adjusted $\left(\rho=0.91^{3}\right)$ to match our quarterly frequency.

${ }^{21}$ Here, making marginal cost depend on firms' own output would be beneficial. 
of 0.05 .

- Price indexation: $\gamma_{p}=0.3$. Our model allows for persistent marginal costs through persistent technology shocks and additionally through persistence of wages. We therefore set price indexation to the rather small value of 0.3 . This is in line with the euro area evidence reported in Gali, Gertler, and LópezSalido (2001). For comparison, Smets and Wouters (2003) estimate a posterior mode value of 0.4 which given their prior corresponds to a value more than two standard deviations below their prior mean. We allow for a wide standard deviation of 0.1 in order to accommodate other values of $\gamma_{p}$.

- Weight on the number of job-seekers in matching: $\sigma_{2}=0.4$. We take a prior standard deviation of 0.05 .

- Wage indexation: $\phi_{L}^{\text {new }}=0.25$. This value was chosen on the basis of experimentation. To the best of our knowledge no independent evidence exists that would help to fix this parameter. We allow for a (in our view and experience) wide standard deviation of 0.1 on our prior.

Next we turn to our priors for the serial correlation of the shocks, which are important for determining the system's dynamics. Some of the serial correlation parameters are at the boundary of values suggested in the literature. This is largely due to our modeling strategy that we try to be as parsimonious as possible with respect to introducing shocks. We see this as a virtue of our approach.

- Shock to inflation target: $\rho_{e \bar{\pi}}=0.3$. Smets and Wouters (2003) allow for two "monetary policy shocks": one persistent shock to the inflation target and additionally one serially uncorrelated innovation. Our prior tries to strike a compromise but allows for a broad standard deviation of 0.2 .

- Shock to vacancy posting costs: $\rho_{e \kappa}=0.7$. Vacancy posting costs are a catch-all for impediments to setting up firms/hiring workers. As such, our prior dictates 
that these ought to be somewhat persistent. We set a prior standard deviation of 0.1 .

- Technology shock: $\rho_{e z}=0.9$. We impose a prior for the technology shock that is in line with the values conventionally used in the RBC literature for quarterly data. We set a standard deviation of 0.025 .

- Shock to disutility of work: $\rho_{e \kappa h}=0.3$. This shock will loosen the connection between the very persistent technology shock and wages. Smets and Wouters (2003) assume that labor supply shocks themselves are very persistent. However, they on top of this also introduce an iid "wage mark-up shock". Economically, our disutility of work shock mixes these two disturbances. We allow for a standard deviation of 0.1 in our prior.

- Cost-push and demand shocks are assumed to be i.i.d.

All priors for the standard deviations follow inverse gamma distributions. The exception being the innovation to the disutility of work shock: there we use a tighter normal prior to explicitly restrict the support of this innovation. 


\section{Estimation Results}

In our empirical study, we employ quarterly German data from 1977:1 to 2004:2; see Appendix B for details on the sources and properties of the data. Thirty of these observations are used for presampling so that the observation sample starts in 1984:3. Much of the recent debate in the labor market literature (see e.g. Hall, 2005, and Shimer, 2005) has focused on the variability of vacancies. Hall (2005), in an efficient bargaining framework, shows that if the labor share is sufficiently large and the wage bill does not fluctuate much, profits (and the profit share) fluctuate considerably. This in turn induces the number of vacancies to fluctuate as much as in the data - a fact the matching model had been criticized not being able to match. In a right-to-manage framework, up to first order, the labor share is determined by technology, not by bargaining power (and, besides, is constant over time). We therefore are not able to exactly match the volatility of vacancies in the data. As emphasized by Christoffel and Linzert (2005), however, right-to-manage bargaining introduces a direct channel from wages to inflation. We weigh the advantages of both bargaining schemes and decide to pursue right-to-manage here. Consequently we do not treat vacancies as an observable variable in our estimation.

As for hours worked, these are notoriously imprecisely measured in the German data. The specific choice of the time-series for hours would have considerably influenced our results. We therefore decide not to treat hours worked as one of our observable variables but limit ourselves to fitting consumption, employment, real wages, (consumer price) inflation and nominal interest rates.

Table 9 shows our posterior estimates for the model parameters. The Taylor rule estimates are standard and in line with the evidence by Clarida, Gali, and Gertler (1998). Our estimate of habit persistence, $h_{c}=0.83$, is somewhat larger than usually found in the literature. This may be attributed to the fact that we do not allow for serially correlated demand shocks. The Calvo probability, $\varphi=0.92$, is larger than the prior mean. The degree of stickiness seems to be too high, even in light of German 
Table 1: Estimated Posterior Maximum Parameters

\begin{tabular}{|c|c|c|c|c|c|c|}
\hline \multirow[t]{2}{*}{ Parameter } & \multicolumn{3}{|c|}{ prior } & \multicolumn{2}{|c|}{ posterior } & \multirow[t]{2}{*}{ "t-stat" } \\
\hline & mean & std & distr. & mode & std & \\
\hline \multicolumn{7}{|c|}{ Parameters of Structural Model } \\
\hline$\rho_{m}$ & 0.750 & 0.0500 & norm & 0.7852 & 0.0347 & 22.6258 \\
\hline$\gamma_{\pi}$ & 1.500 & 0.3000 & norm & 1.4020 & 0.2396 & 5.8514 \\
\hline$\gamma_{y}$ & 0.125 & 0.3000 & norm & 0.1907 & 0.0579 & 3.2915 \\
\hline$h_{c}$ & 0.850 & 0.0500 & norm & 0.8295 & 0.0324 & 25.5776 \\
\hline$\varphi$ & 0.900 & 0.0500 & norm & 0.9242 & 0.0138 & 67.1596 \\
\hline$\gamma_{p}$ & 0.300 & 0.1000 & norm & 0.2638 & 0.0691 & 3.8164 \\
\hline$\sigma_{2}$ & 0.400 & 0.0500 & norm & 0.3113 & 0.0505 & 6.1666 \\
\hline$\phi_{L}^{n e w}$ & 0.250 & 0.1000 & norm & 0.3622 & 0.0515 & 7.0392 \\
\hline \multicolumn{7}{|c|}{ Serial Correlation of Shocks } \\
\hline$\rho_{\bar{\pi}}$ & 0.300 & 0.2000 & norm & 0.3554 & 0.0982 & 3.6178 \\
\hline$\rho_{\kappa}$ & 0.700 & 0.1000 & norm & 0.5973 & 0.0630 & 9.4833 \\
\hline$\rho_{z}$ & 0.900 & 0.0250 & norm & 0.9339 & 0.0251 & 37.1918 \\
\hline$\rho_{\kappa_{h}}$ & 0.300 & 0.1000 & norm & 0.2040 & 0.0845 & 2.4139 \\
\hline \multicolumn{7}{|c|}{ Standard Deviation of Innovations } \\
\hline$\mu^{\bar{\pi}}$ & 0.007 & Inf & invg & 0.0028 & 0.0006 & 4.8168 \\
\hline$\mu^{p r e f}$ & 0.100 & Inf & invg & 0.0683 & 0.0130 & 5.2528 \\
\hline$\mu^{z}$ & 0.006 & Inf & invg & 0.0042 & 0.0012 & 3.6615 \\
\hline$\mu^{\text {cost-push }}$ & 0.001 & Inf & invg & 0.0029 & 0.0003 & 11.1078 \\
\hline$\mu^{\kappa}$ & 0.010 & Inf & invg & 0.0253 & 0.0062 & 4.1023 \\
\hline$\mu^{\kappa_{h}}$ & 0.200 & 0.1000 & norm & 0.4350 & 0.0564 & 7.7181 \\
\hline
\end{tabular}

Notes: Estimates of the posterior mode. The standard deviation is obtained by a Gaussian approximation at the posterior mode. "t-stat" refers to the mode estimate divided by by posterior marginal standard deviation. Nota bene: The underlying calibration is such that $\bar{q}=0.7391, \bar{s}=0.4928, \bar{w} \bar{h} / \bar{y}=\alpha=0.72, \bar{\kappa} /(\bar{\lambda} \bar{y})=1.4771$, $b /(\bar{w} \bar{h})=0.5, \bar{u}=0.15$ and $\bar{v}=0.1$.

micro studies. Bringing this estimate down to reasonable numbers recently has been the scope of a growing literature; see Altig, Christiano, Eichenbaum, and Linde (2005) and Eichenbaum and Fisher (2003), for instance. We seek to explore this in future research. We find a low degree of price indexation, $\gamma_{p}=0.26$. Finally, the weight on unemployment in the matching process is estimated to be well below half, $\sigma_{2}=0.31$. New matches in Germany according to our model estimates are driven by vacancies rather than by the pool of unemployed workers.

Turning to shock persistence, our results seem in line with the literature. Worth 
mentioning is that labor market friction shocks (vacancy posting shocks) are estimated to be quite persistent, $\rho_{\kappa}=0.6$. Innovation standard deviations look standard but for the innovation to the disutility of work, $\mu^{\kappa_{h}}$. Its value is 0.44 , well above its prior mean and, from an economic perspective, at the border of being reasonable.

For the estimation, we have fixed the elasticity of intertemporal substitution to unity, $\sigma=1$, and the labor supply elasticity to a small value, $1 / \phi=0.1$. In contrary to other macroeconomic studies the model provides a good fit employing the low labor supply elasticity found in micro studies. Introducing the extensive margin into the macro-model helps reconciliate macro and micro evidence without compromising on fit.

As a measure of fit, Table 2 reports how well the standard deviations of the endogenous

Table 2: Compare Model Second Moments to Data

\begin{tabular}{lccccc}
\hline \hline Variable & RMSE (model) & RMSE (VAR) & std (model) & std (data) & std (VAR) \\
\hline$\widehat{y}_{t}$ & 0.0109 & 0.0096 & 0.0167 & 0.0173 & 0.0166 \\
$\widehat{r}_{t}$ & 0.0009 & 0.0008 & 0.0036 & 0.0044 & 0.0037 \\
$\widehat{\pi}_{t}^{a n n}$ & 0.0037 & 0.0040 & 0.0147 & 0.0132 & 0.0110 \\
$\widehat{n}_{t}$ & 0.0043 & 0.0038 & 0.0085 & 0.0109 & 0.0103 \\
$\widehat{w}_{t}$ & 0.0062 & 0.0058 & 0.0239 & 0.0223 & 0.0165 \\
\hline
\end{tabular}

Notes: The table compares the root mean squared forecast error of the model evaluated at the posterior mode (second column) to the root mean squared forecast errors resulting from a VAR(2) in the sample 1984:3 - 2004:2 (third column). The fourth to sixth column compare the standard deviations implied by the model to those taken directly from the data and those taken from an auxiliary $\operatorname{VAR}(2)$. Nota bene: standard deviation of hours (very dependent on the choice of the data series): 0.0210 (model) vs. 0.05328 (data); standard deviation of vacancies: 0.0817 (model) vs. 0.3016 (data)

variables in our model match with the time-series evidence. To that aim, we compare the model standard deviations to those taken directly from the data and those taken from an auxiliary $\operatorname{VAR}(2)$ model. Overall, our model seems to fit the second moments of the data rather well. When it comes to comparing root mean squared errors, only the consumption equation falls behind a $\operatorname{VAR}(2)$ in terms of forecast performance. That the model explains the data well is corroborated also by the marginal data densities displayed in Table 3.

Table 4 illustrates that the persistence of real wages and inflation implied by the model 
Table 3: Log Marginal Data Densities

\begin{tabular}{lccccc}
\hline \multicolumn{2}{c}{ BVAR(1) } & \multicolumn{2}{c}{ BVAR(2) } & \multicolumn{2}{c}{ Model } \\
true & Laplace & true & Laplace & Laplace & Harm. Mean \\
\hline 1586.43 & 1585.66 & 1576.32 & 1574.25 & 1609.83 & 1609.86 \\
\hline
\end{tabular}

Notes: Marginal data density of Bayesian VARs under flat priors, using a Laplace approximation and the exact formula each, and the model data density using a Laplace approximation and the modified harmonic mean.

is very similar to the persistence found in the data (compare also Table 7 in Appendix $\mathrm{E})$.

Table 4: Persistence Measures

\begin{tabular}{lccccc}
\hline Variable & $\beta_{1}$ & $\beta_{1}+\beta_{2}$ & $\beta_{1}+\ldots+\beta_{3}$ & $\beta_{1}+\ldots+\beta_{4}$ & $\beta_{1}+\ldots+\beta_{5}$ \\
\hline$\widehat{w}_{t}$ & $0.94(0.93)$ & $0.92(0.92)$ & $0.92(0.91)$ & $0.92(0.93)$ & $0.92(0.92)$ \\
$\widehat{\pi}_{t}^{\text {ann }}$ & $0.93(0.93)$ & $0.90(0.92)$ & $0.89(0.91)$ & $0.89(0.89)$ & $0.93(0.91)$ \\
\hline \hline
\end{tabular}

Notes: Shown is the sum up to the first five regression coefficients when regressing the relevant variable on its own lags (evaluated at the posterior mode). Regression coefficients are based on the estimated model. In brackets are the values measured in the data.

As a further measure of fit, in Figure 1 we compare model cross-correlations to those of the data. The black solid line marks model cross-correlations (evaluated at the posterior mode, again). The figure also shows $\operatorname{VAR}(2)$ cross-correlations (read and dotted) as a data summary. These are framed by dotted blue 95\% bootstrapped confidence intervals. Overall, the model cross-correlations match the data's well especially the autocorrelation properties. Still, a few properties are not matched by our model. First, the correlation between consumption and interest rates is not strong enough (row 1, column 2; row 2, column 1). Second, our model also does not match well enough the fact that consumption is a predictor for future inflation (row 1, column 3; row 3, column 1). Presumably, these correlations could be brought closer to the data by a more judicious and contrived choice of the monetary policy rule. In our model, the monetary authority is the only sector which is not optimizing. In principle that leaves many degrees of freedom for modelling the interest rate reaction function. However, more sophisticated (performance oriented) policy rules may tend to overfit - making policy-analysis on the basis of the model a dubious task. We prefer to stick to the parsimonious Taylor rule. Third, the set of cross-correlations does not seem to 
Figure 1: Cross-Correlations.

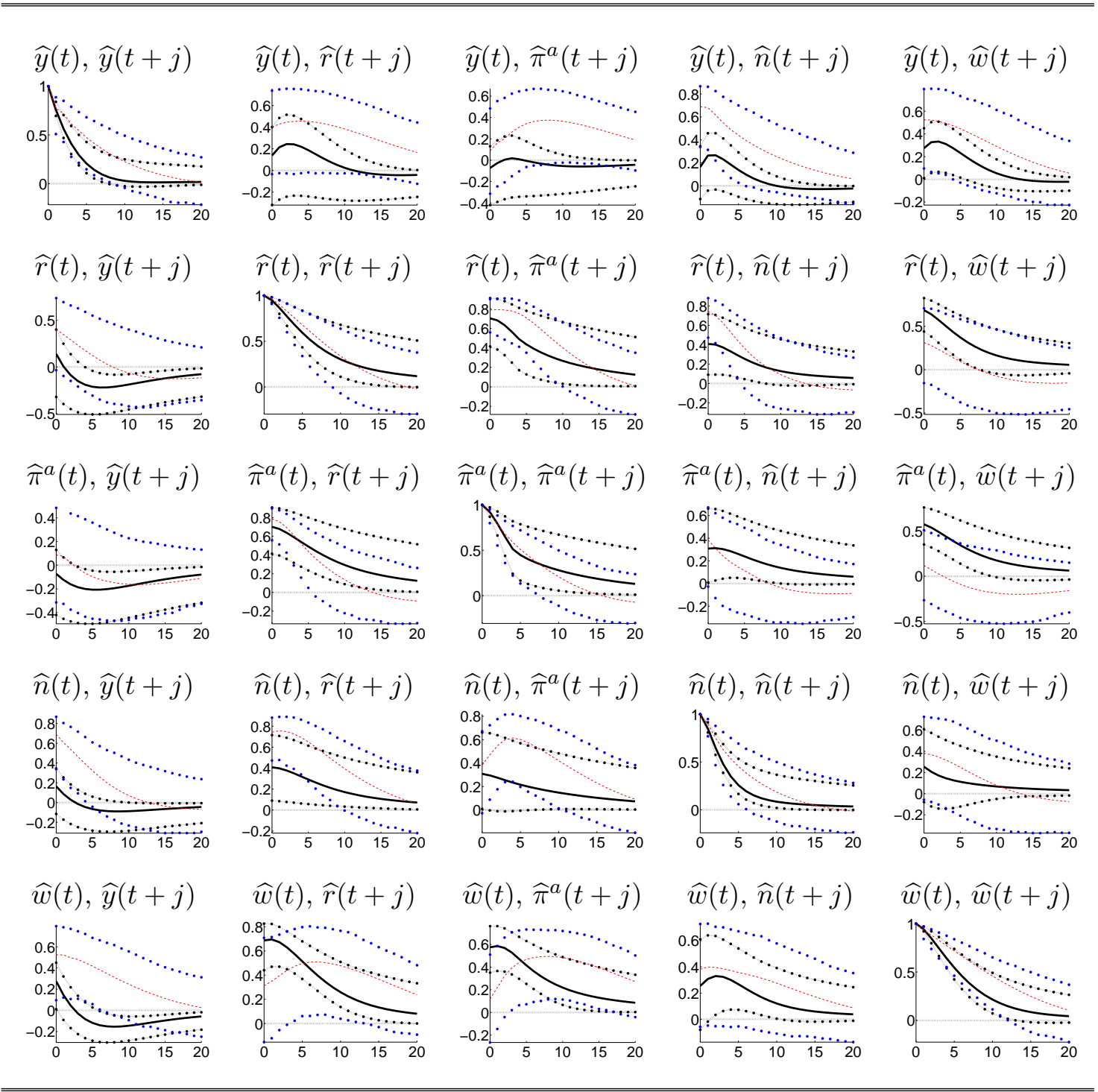

Notes: Autocorrelation vs data (VAR2). The black solid line marks the cross-correlation of the model at the posterior mode (or, it turns out after the simulations, almost equivalently the median crosscorrelation). The black dash-dotted lines mark corresponding $95 \%$ posterior coverage intervals (over the median). The red dashed line marks cross-correlations obtained from a VAR(2) without constants. Blue dots mark a $95 \%$ confidence interval (over the median) obtained from bootstrapping the same $\operatorname{VAR}(2)$ without constant. 
completely match all properties of the data: both employment and the real wage are not sufficiently positively correlated with future output (rows 4 and 5, column 1).

We next turn to the propagation mechanism of shocks and ultimately to the policy considerations. 


\section{The Impact of the Labor Market on Model Dynamics}

In this section, we analyze the dynamics of the estimated model. Towards that aim, we present empirical impulse response functions as well as forecast error variance decompositions. In particular, we investigate the specific role of the labor market for the model's dynamics. Additionally, we will present counterfactual scenarios illustrating the dynamics of the economy in different labor market regimes. We will specifically analyze how the economy responds to shocks in more flexible labor market environments and also look at the response when wages are assumed to be flexible.

In a first step, we investigate the labor market's implication for the transmission of economic shocks. We are particularly interested in how a monetary policy shock is transmitted in the presence of a non-Walrasian labor market. An increase in the inflation target in our model corresponds to the central bank decreasing its key interest rate (see the solid line in Figure 2). The lowered rate reduces savings and increases household consumption. The increased demand in turn requires additional labor input. Due to the rigidities in the labor market the number of employed workers cannot be increased instantly. ${ }^{22}$ Hence labor adjustment is initially implemented via an increase of hours worked per employee. The increased demand boosts expected profits and vacancy posting increases until expected profits equal the posting costs. In anticipation of higher profits the value of an employment relation increases and workers aspire higher wages. Firms' marginal cost of production increase with higher wage rates implying higher prices and higher inflation (see Figure 2).

Figure 2 also shows a counterfactual exercise illustrating the impact of wage rigidity. ${ }^{23}$ We compare the response to an inflation target shock in the estimated model with the response in a model assuming flexible wages. ${ }^{24}$ Given full wage flexibility, profits

\footnotetext{
22 Although this would be beneficial due to decreasing returns to labor.

${ }^{23}$ A detailed description of all the counterfactual exercises can be found in Appendix E.

24 The red dotted line marked by triangles in Figure 2 shows the impulse responses when wage rigidity is eliminated. Towards that aim, we set the wage adjustment cost parameter $\phi_{L}^{n e w}$ to zero.
} 
Figure 2: Impulse Responses to 1\% Inflation Target Shock.

Consumption

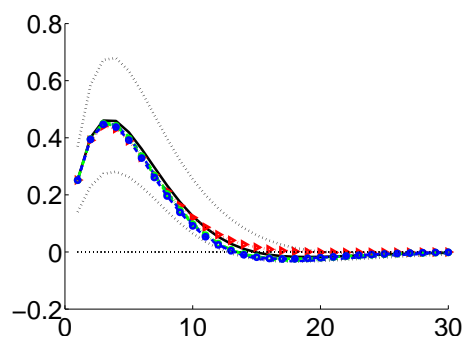

Unemployment

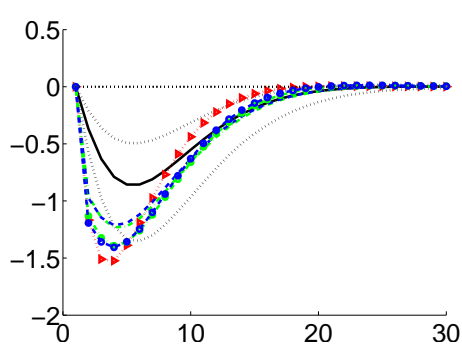

Hours

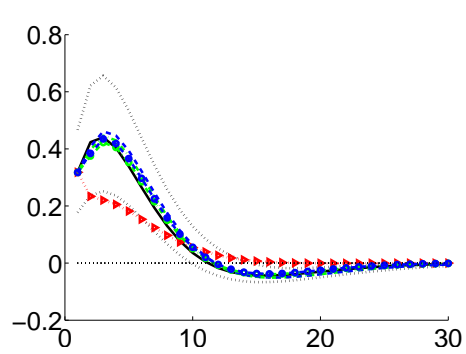

Quarterly Inflation

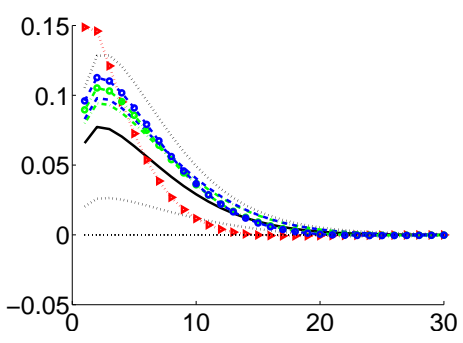

Vacancies

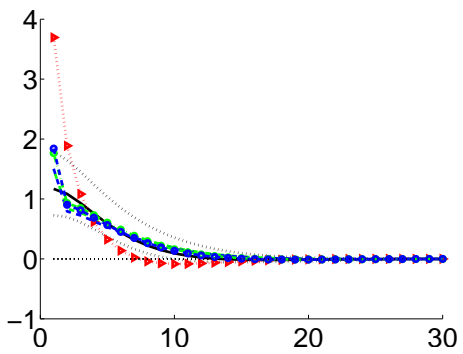

Marginal Cost

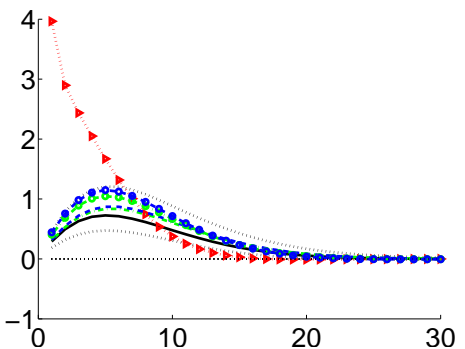

Nominal Rate

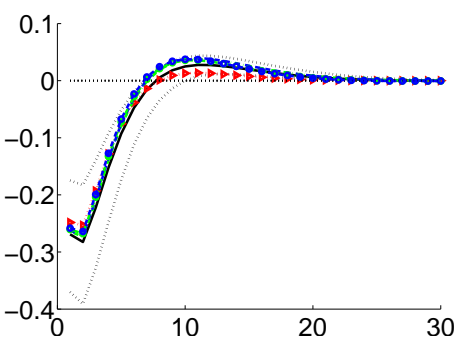

Profits

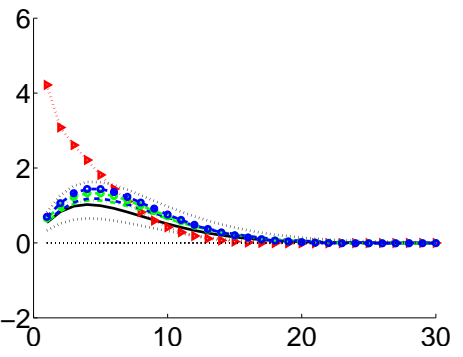

Real Wage Rate

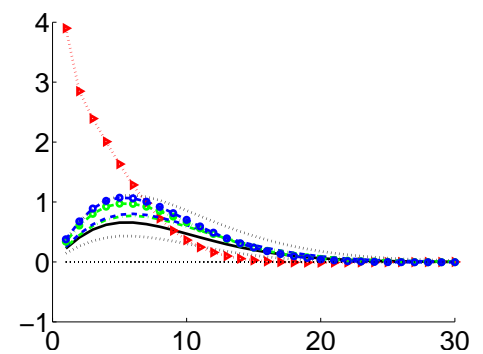

Notes: The figures show percentage responses ( 1 in the plots corresponds to $1 \%$ ) of endogenous variables to a one percent increase in the inflation target. The black solid line marks the estimated model (at the posterior mode). Black dotted lines mark 95\% confidence intervals (using 100.000 draws from the posterior distribution). The red line marked by triangles shows the case of no wage rigidity. The remaining blue and green lines correspond to the counterfactual flexible labor market experiments described in more detail in Appendix E. Nb: an increase of unemployment of 1 in the plot means that the unemployment rate increases by $1 \%$, say from 0.15 to 0.1515 ; not by one percentage point! 
increase more sharply after a monetary policy shock leading to a correspondingly stronger increase in real wages. This in turn triggers a stronger response of inflation compared to the model with rigid wages. Therefore, introducing wage rigidity in the right-to-manage model smoothes wages as well as marginal cost so that the wage induced inertia in marginal costs translates into more persistent inflation via the new Keynesian Phillips curve. In terms of the response of unemployment, more flexible wages yield a stronger fall of unemployment. In addition, unemployment appears to be somewhat less persistent than under a regime of rigid wages. ${ }^{25}$

Additionally, Figure 2 shows the second counterfactual exercise comparing the responses of the variables in the estimated model to an inflation target shock with the one under a flexible labor market regime (see the dotted blue and green lines in the figure). The labor market is less rigid in the following sense: We assume that all workers immediately find a job in steady state, which corresponds to an abundance of firms in the market. We do, however, retain the wage rigidity. An increase in the inflation target decreases the real interest rate leading to an increase in consumption. Hence profits rise and vacancies increase accordingly. In a more flexible labor market regime, labor market tightness is affected more strongly by movements in unemployment. This in turn translates into larger movements in wages and also inflation than in the rigid baseline. Therefore, we conclude that in our model more rigid labor markets, especially when rigidities lie on the wage side, lead to more persistent movements in inflation. This implies that the transmission mechanism of monetary policy is influenced by the degree of rigidities in the labor market.

In a second step, we look directly at the impact of the labor market. Towards that aim, we proxy labor market impediments by the cost of vacancy posting. We analyze how a shock to vacancy posting affects the nominal and real variables in our model (see the solid black line in Figure 3). In our simulations, a vacancy posting cost shock increases the costs of posting a vacancy by $1 \%$. Vacancy posting activity decreases with the job

\footnotetext{
25 Notice that due to income pooling the labor market dynamics do not translate into changes in the behavior of consumption.
} 
destruction rate remaining constant by assumption. Hence unemployment increases. Hours worked need to increase to satisfy consumption demand. Consumption itself is affected only slightly due to the assumption of strong habits and income pooling. Rising job creation costs increase the value of existing employment relations which leads to a rise in wages and profits, and ultimately inflation.

Figure 3) also shows the response of the variables to a vacancy posting cost shock under a flexible wage regime. An increase in vacancy posting cost depresses vacancy postings as before. Profits of operating firms rise to a greater extent than in the baseline. Higher profits in turn lead to higher wages and higher marginal costs translating into an increased response of inflation. Consequently, that means that vacancies experience a smaller drop and unemployment rises by less than in the benchmark.

Closely watching labor market developments could be important for monetary policy makers if these developments ultimately have an effect on inflation and consumption and if the traditional New Keynesian variables are not sufficient statistics in this respect. The variance decomposition in Table 5 shows how much of the forecast error variance in each variable at different forecast horizons is due to a specific set of innovations.

The vacancy posting cost shock is the key driving force of employment ( $87 \%$ in the short-run and $63 \%$ in the long run) and vacancies (roughly $80 \%$ in the short and longrun). It is also an important determinant for wages, hours worked and marginal cost (roughly $10 \%$ to $15 \%$ in the short and long run) but with not enough transmission to let it matter for inflation or consumption. As is apparent from Table 5 less than 5 percent of the variation of inflation, output and interest rates is driven by labor market shocks. This result holds at all frequencies. ${ }^{26}$ We can conclude that the impact of shocks to vacancy posting on nominal and real variables of the model is rather limited.

\footnotetext{
${ }^{26}$ One likely reason for the limited impact of labor market shocks on output and inflation lies in the very structure of our model economy. In particular, we assume that households pool their income to insure against income reductions caused by unemployment and that more input of hours worked can substitute for employment. Taken together, this implies that aggregate consumption is rather immune to the state of the labor market.
} 
Figure 3: Impulse Responses to 1\% Vacancy Posting Cost Shock.

Consumption

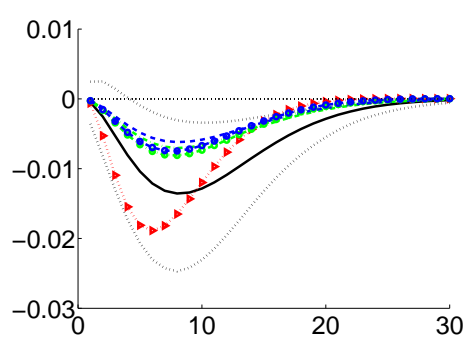

Unemployment

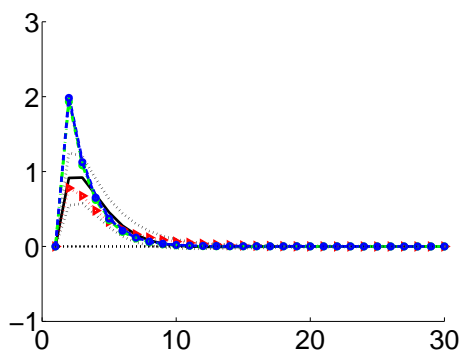

Hours

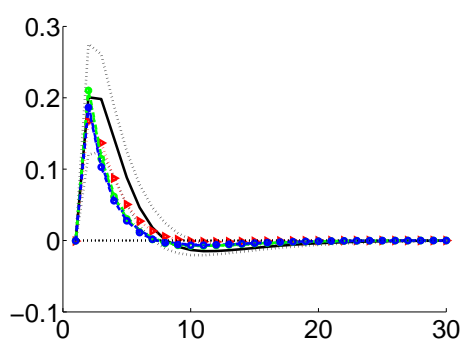

Quarterly Inflation

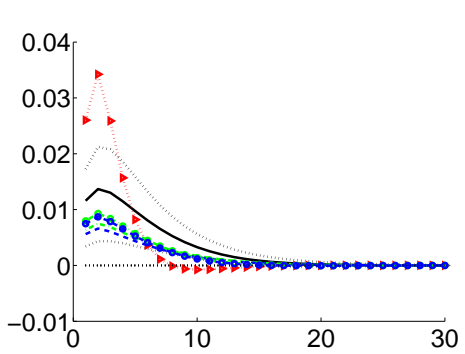

Vacancies
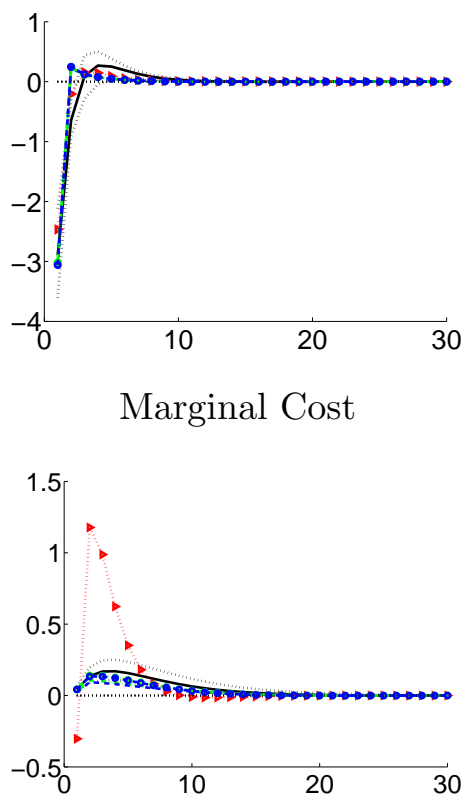

Nominal Rate

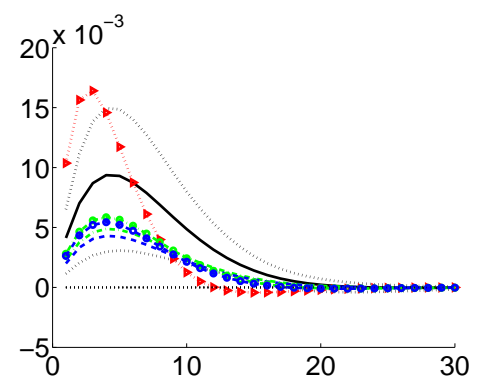

Profits
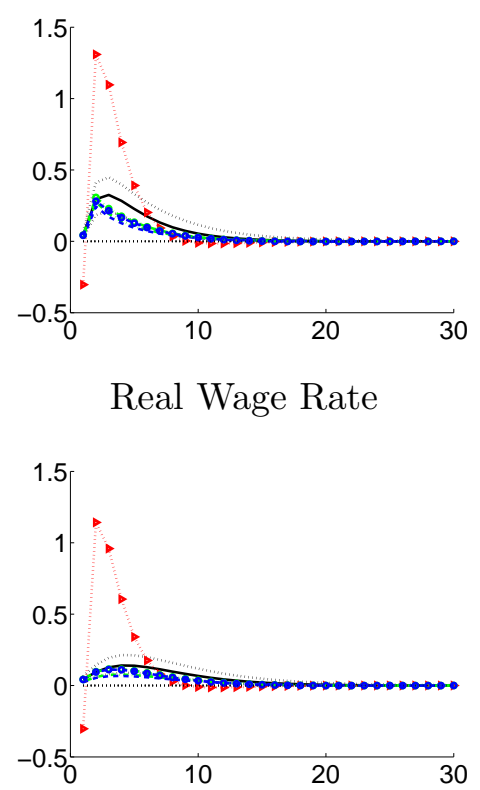

Notes: The figures show percentage responses (1 in the plots corresponds to $1 \%$ ) of endogenous variables to a one percent increase in vacancy posting costs. The black solid line marks the estimated model (at the posterior mode). Black dotted lines mark 95\% confidence intervals (using 100.000 draws from the posterior distribution). The red line marked by triangles shows the case of no wage rigidity. The remaining blue and green lines correspond to the counterfactual flexible labor market experiments described in more detail in Appendix E. Nb: an increase of unemployment of 1 in the plot means that the unemployment rate increases by $1 \%$, say from 0.15 to 0.1515 ; not by one percentage point! 
Table 5: Forecast Error Variance Decomposition

\begin{tabular}{|c|c|c|c|c|c|c|}
\hline Variable & target & demand & techn. & cost-p. & vacancy & dis. labor \\
\hline \multicolumn{7}{|c|}{ Horizon 2} \\
\hline$\widehat{y}_{t}$ & 00.89 & 99.08 & 00.02 & 00.01 & 00.00 & 00.00 \\
\hline$\widehat{r}_{t}$ & 50.39 & 28.57 & 12.41 & 06.25 & 01.24 & 01.15 \\
\hline$\widehat{\pi}_{t}^{a n n}$ & 00.35 & 01.50 & 08.68 & 87.65 & 00.86 & 00.96 \\
\hline$\widehat{n}_{t}$ & 00.19 & 08.62 & 03.69 & 00.00 & 86.52 & 00.99 \\
\hline$\widehat{w}_{t}$ & 01.46 & 24.31 & 07.05 & 00.04 & 05.83 & 61.31 \\
\hline$\widehat{x}_{t}$ & 01.02 & 28.36 & 37.18 & 00.02 & 05.02 & 28.40 \\
\hline$\widehat{h}_{t}$ & 00.62 & 79.25 & 12.70 & 00.00 & 07.32 & 00.11 \\
\hline$\widehat{v}_{t}$ & 00.32 & 09.87 & 04.74 & 00.01 & 83.90 & 01.17 \\
\hline \multicolumn{7}{|c|}{ Horizon 10} \\
\hline$\widehat{y}_{t}$ & 03.25 & 93.59 & 02.72 & 00.13 & 00.18 & 00.13 \\
\hline$\widehat{r}_{t}$ & 17.55 & 37.84 & 38.21 & 02.14 & 02.50 & 01.77 \\
\hline$\widehat{\pi}_{t}^{a n n}$ & 01.60 & 04.34 & 43.01 & 45.41 & 03.16 & 02.48 \\
\hline$\widehat{n}_{t}$ & 01.62 & 15.80 & 14.53 & 00.07 & 65.97 & 02.02 \\
\hline$\widehat{w}_{t}$ & 04.97 & 30.03 & 16.81 & 00.24 & 15.20 & 32.74 \\
\hline$\widehat{x}_{t}$ & 03.26 & 24.15 & 44.33 & 00.16 & 11.02 & 17.08 \\
\hline$\widehat{h}_{t}$ & 01.48 & 69.45 & 13.11 & 00.05 & 14.90 & 01.03 \\
\hline$\widehat{v}_{t}$ & 00.57 & 09.99 & 06.13 & 00.02 & 82.09 & 01.20 \\
\hline \multicolumn{7}{|c|}{ Horizon 40} \\
\hline$\widehat{y}_{t}$ & 03.12 & 88.64 & 07.65 & 00.13 & 00.28 & 00.19 \\
\hline$\widehat{r}_{t}$ & 14.46 & 31.99 & 48.10 & 01.75 & 02.19 & 01.51 \\
\hline$\widehat{\pi}_{t}^{a n n}$ & 01.47 & 03.68 & 52.29 & 37.67 & 02.76 & 02.12 \\
\hline$\widehat{n}_{t}$ & 01.75 & 15.19 & 18.17 & 00.09 & 62.85 & 01.96 \\
\hline$\widehat{w}_{t}$ & 05.39 & 28.33 & 20.77 & 00.28 & 14.83 & 30.41 \\
\hline$\widehat{x}_{t}$ & 03.26 & 21.37 & 50.16 & 00.16 & 10.00 & 15.04 \\
\hline$\widehat{h}_{t}$ & 01.49 & 69.33 & 13.05 & 00.05 & 14.95 & 01.14 \\
\hline$\widehat{v}_{t}$ & 00.57 & 09.97 & 06.38 & 00.02 & 81.85 & 01.20 \\
\hline
\end{tabular}

Notes: Forecast error variance demcoposition for three different forecast horizons evaluated at the posterior mode. From top to bottom: consumption, nominal interest rate, annual inflation, employment, real wage rate, real marginal cost, hours worked, vacancies. From left to right: inflation target shock, demand (preference) shock, technology shock, cost-push shock, vacancy posting cost shock, disutility of work shock. All entries are in \%. 
Figure 4: Impulse Responses to 1\% Technology Shock.

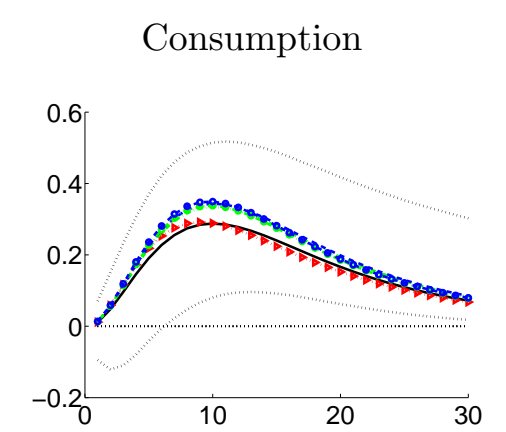

Unemployment

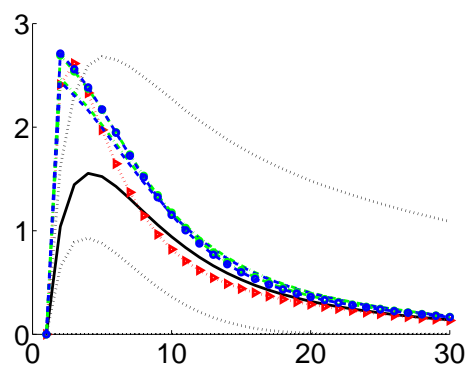

Hours

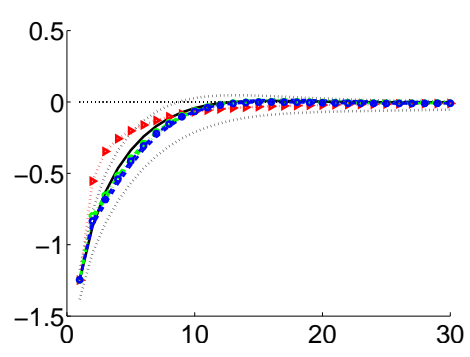

Quarterly Inflation

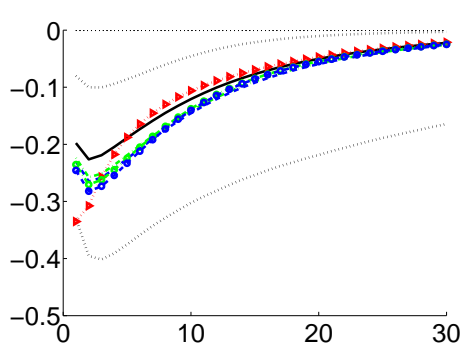

Vacancies

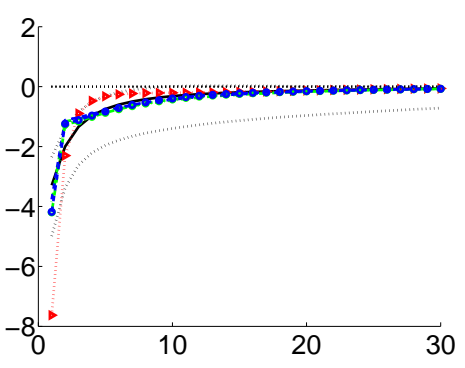

Marginal Cost

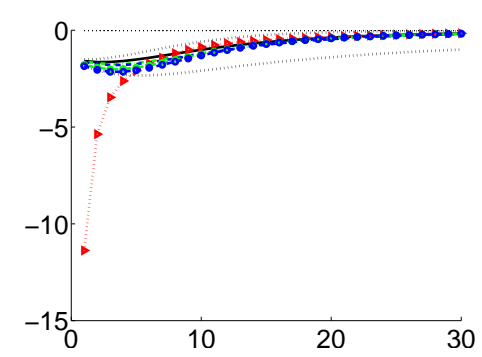

Nominal Rate
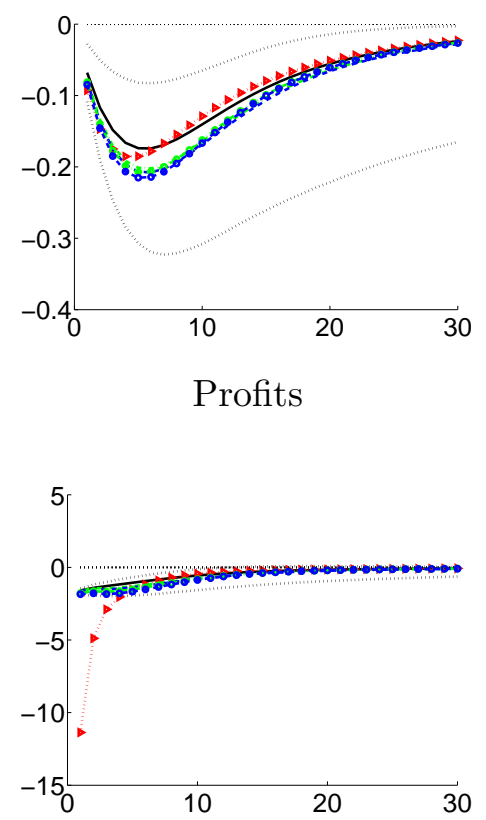

Real Wage Rate

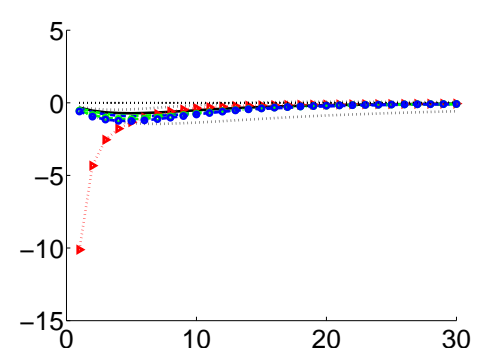

Notes: The figures show percentage responses (1 in the plots corresponds to $1 \%$ ) of endogenous variables to a one percent technology shock. The black solid line marks the estimated model (at the posterior mode). Black dotted lines mark 95\% confidence intervals (using 100.000 draws from the posterior distribution). The red line marked by triangles shows the case of no wage rigidity. The remaining blue and green lines correspond to the counterfactual flexible labor market experiments described in more detail in Appendix E. Nb: an increase of unemployment of 1 in the plot means that the unemployment rate increases by $1 \%$, say from 0.15 to 0.1515 ; not by one percentage point! 
Finally, we take a closer look at the labor market itself. We see that besides the vacancy posting cost shock and the disutility of work shock, labor market variables are especially influenced by technology and demand shocks. In contrast, the inflation target shock and the cost push shock are irrevelant for labor market fluctuations. ${ }^{27}$ In general, unsystematic monetary policy does not appear to be an important determinant of fluctuations - according to our model.

The disutility of works shock governs $60 \%$ of the real wage and $30 \%$ of marginal cost fluctuations in the short run decreasing to $30 \%$ and $15 \%$, respectively, in the long run.

The Keynesian nature of our model becomes most apparent when examining the effect of a positive technology shock (see Figure 4). Hours worked fall as less labor input is required to produce the demand determined output. ${ }^{28}$ This reinforces the increase in the marginal product of labor caused by the technology shock. In addition, the marginal dis-utility of work falls, reducing the real wage rate. Marginal cost fall driven by both the falling wage rate and the increased marginal product of labor. Inflation falls accordingly. The associated interest rate reductions via the central bank reaction function increase consumption gradually. Expected profits are tightly linked to the dynamics in hours and wages. Therefore, lower wages and hours come along with lower profits and hence reduced vacancy posting intensity. This causes a rise in unemployment. The autocorrelated technology shock imposes a significant degree of persistence on the real and nominal variables.

In terms of the variance decomposition, the technology shock is a key determinant of marginal cost (determining 37\% of its fluctuations in the short and $50 \%$ in the long run). Hence productivity fluctuations in our model are very important for inflation, determining $12 \%$ of its variability in the short-run and more than half in the long-run.

\footnotetext{
27 The inflation target shock is rather important for interest rate fluctuations determining $50 \%$ of its fluctuations in the short run and $14 \%$ in the long run. The cost push shock mainly drives the inflation rate and hardly spills over to other variables (apart from interest rates). It explains $88 \%$ of inflation variations in the short-run and still $38 \%$ in the long-run.

28 The response of hours worked to technology shocks recently has caused an intense discussion in the profession. The fall of hours worked in response to a technology shock is in line with evidence reported in Gali (1999) and Francis and Ramey (2002), for instance.
} 
In the long run, technology also plays an important role for real wage and consumption fluctuations. The figures are $20 \%$ and $8 \%$, respectively.

The preference shock stimulates current consumption (see Figure 5). The increased demand requires additional labor input which initially is fully provided by an extension of hours worked. Higher expected profits translate into more vacancy posting and hence into an increase in employment. The demand shock induces a positive correlation between all main variables as it is found in the German data (compare Table 8 for the cross correlations in the data).

Looking at the variance decomposition, it appears that the demand shock drives all consumption movement in the short run and still $89 \%$ in the long run. It explains roughly $30 \%$ of real wage movements and marginal cost. And, indeed as we have argued above, there are other shocks which have more influence on marginal cost and thus on inflation. The demand shock is not a strong driving force of inflation: not more than $5 \%$ of the forecast error variance of inflation fall on the demand shock.

In brief, our results show that the labor market helps to understand the transmission of monetary policy on inflation. Our counterfactual exercises display that the more rigid the labor market, and particularly the real wage is, the more persistent is the response of inflation to an inflation target shock. Moreover, we can show that labor market shocks translate only marginally into the dynamics of nominal variables variables in the model. 
Figure 5: Impulse Responses to 1\% Preference Shock.

Consumption

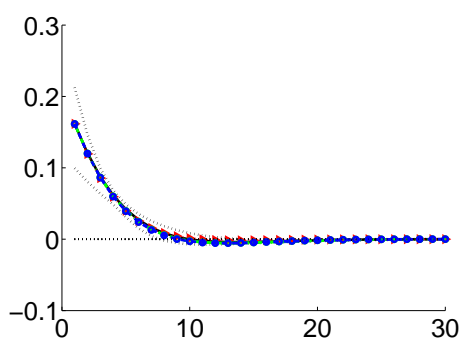

Unemployment

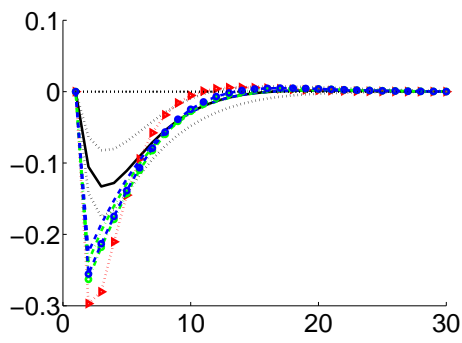

Hours

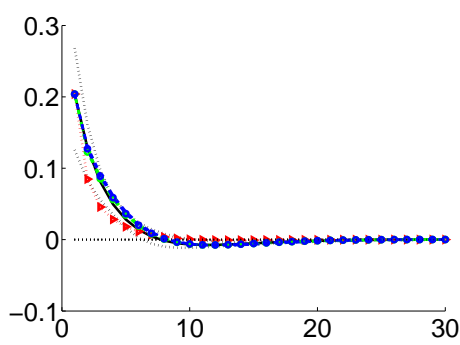

Quarterly Inflation

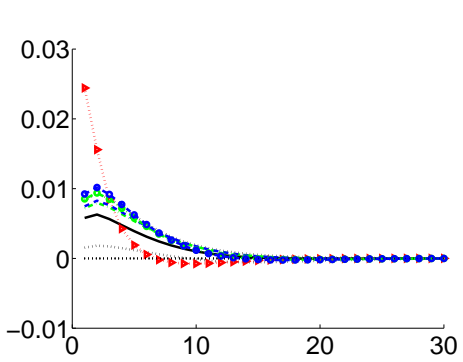

Vacancies

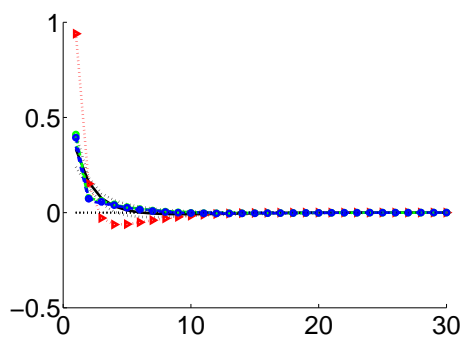

Marginal Cost

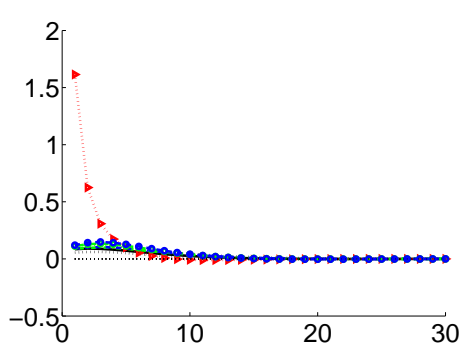

Nominal Rate

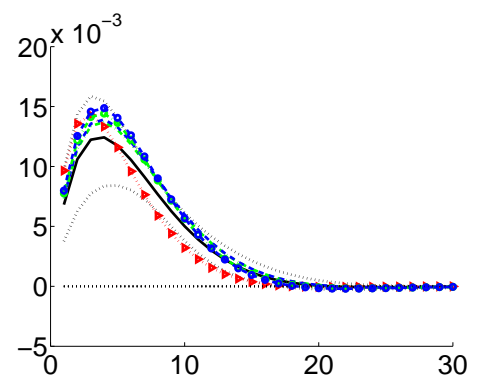

Profits

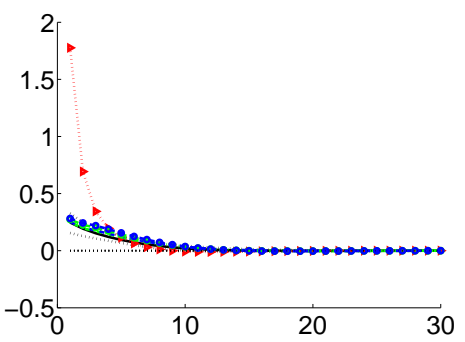

Real Wage Rate

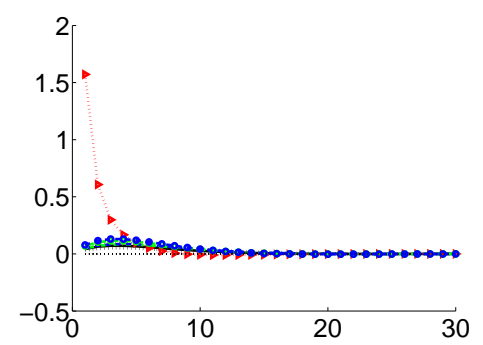

Notes: The figures show percentage responses (1 in the plots corresponds to $1 \%$ ) of endogenous variables to a one percent preference shock. The black solid line marks the estimated model (at the posterior mode). Black dotted lines mark 95\% confidence intervals (using 100.000 draws from the posterior distribution). The red line marked by triangles shows the case of no wage rigidity. The remaining blue and green lines correspond to the counterfactual flexible labor market experiments described in more detail in Appendix E. Nb: an increase of unemployment of 1 in the plot means that the unemployment rate increases by $1 \%$, say from 0.15 to 0.1515 ; not by one percentage point! 
Figure 6: Impulse Responses to 1\% Price-markup Shock.

Consumption

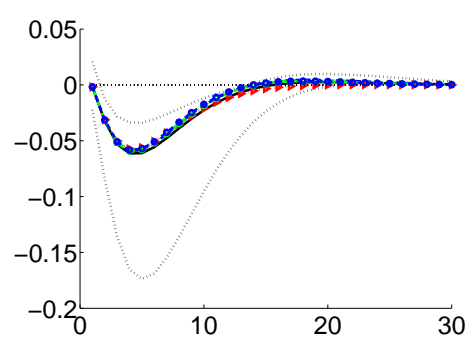

Unemployment

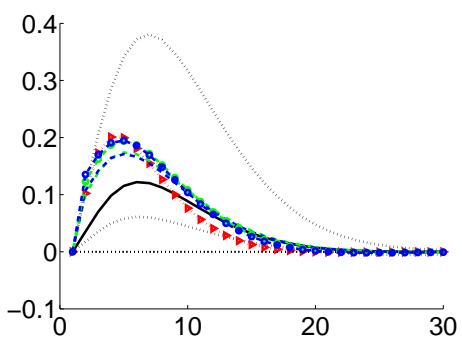

Hours

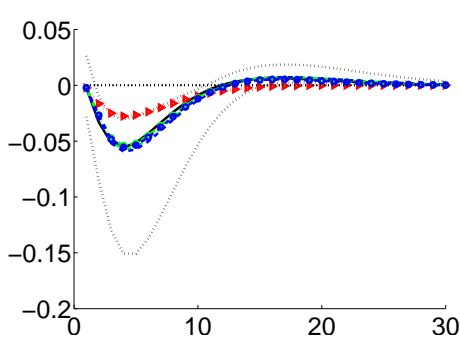

Quarterly Inflation

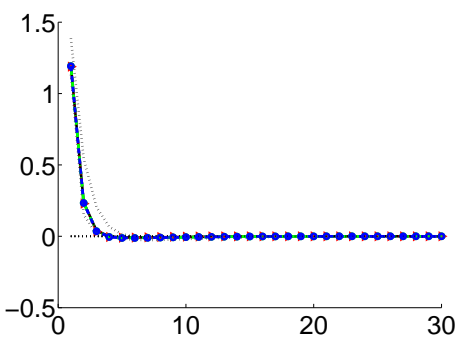

Vacancies
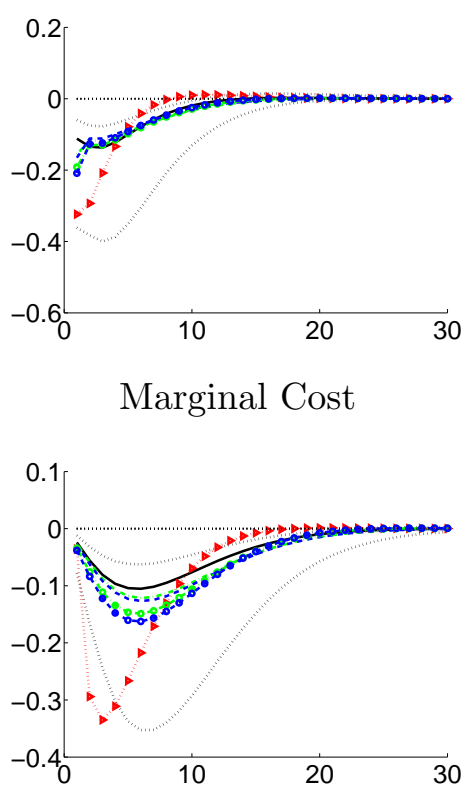

Nominal Rate

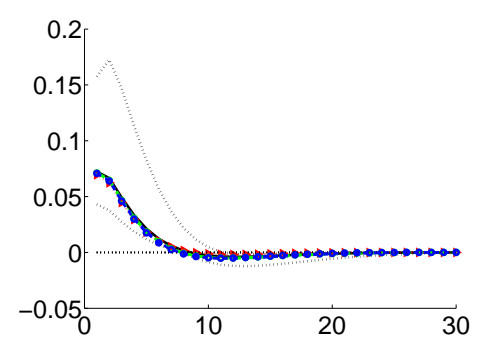

Profits
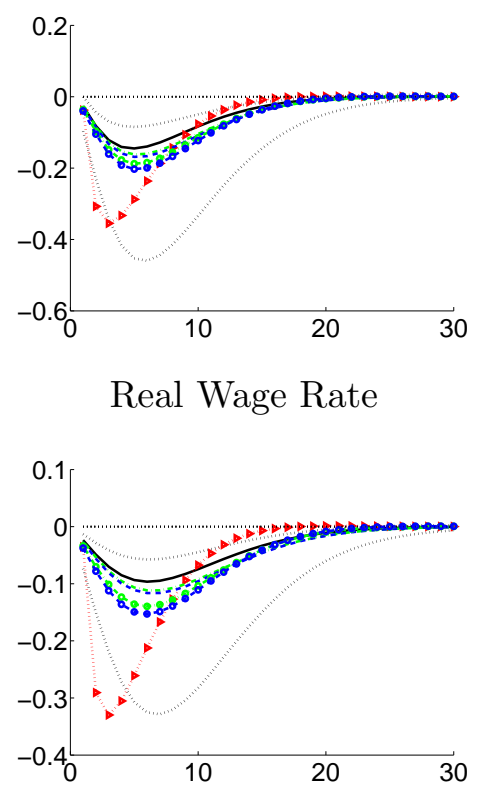

Notes: The figures show percentage responses (1 in the plots corresponds to $1 \%$ ) of endogenous variables to a one percent price-markup shock. The black solid line marks the estimated model (at the posterior mode). Black dotted lines mark 95\% confidence intervals (using 100.000 draws from the posterior distribution). The red line marked by triangles shows the case of no wage rigidity. The remaining blue and green lines correspond to the counterfactual flexible labor market experiments described in more detail in Appendix E. $\mathrm{Nb}$ : an increase of unemployment of 1 in the plot means that the unemployment rate increases by $1 \%$, say from 0.15 to 0.1515 ; not by one percentage point! 
Figure 7: Impulse Responses to 1\% Disutility of Hours Worked Shock.
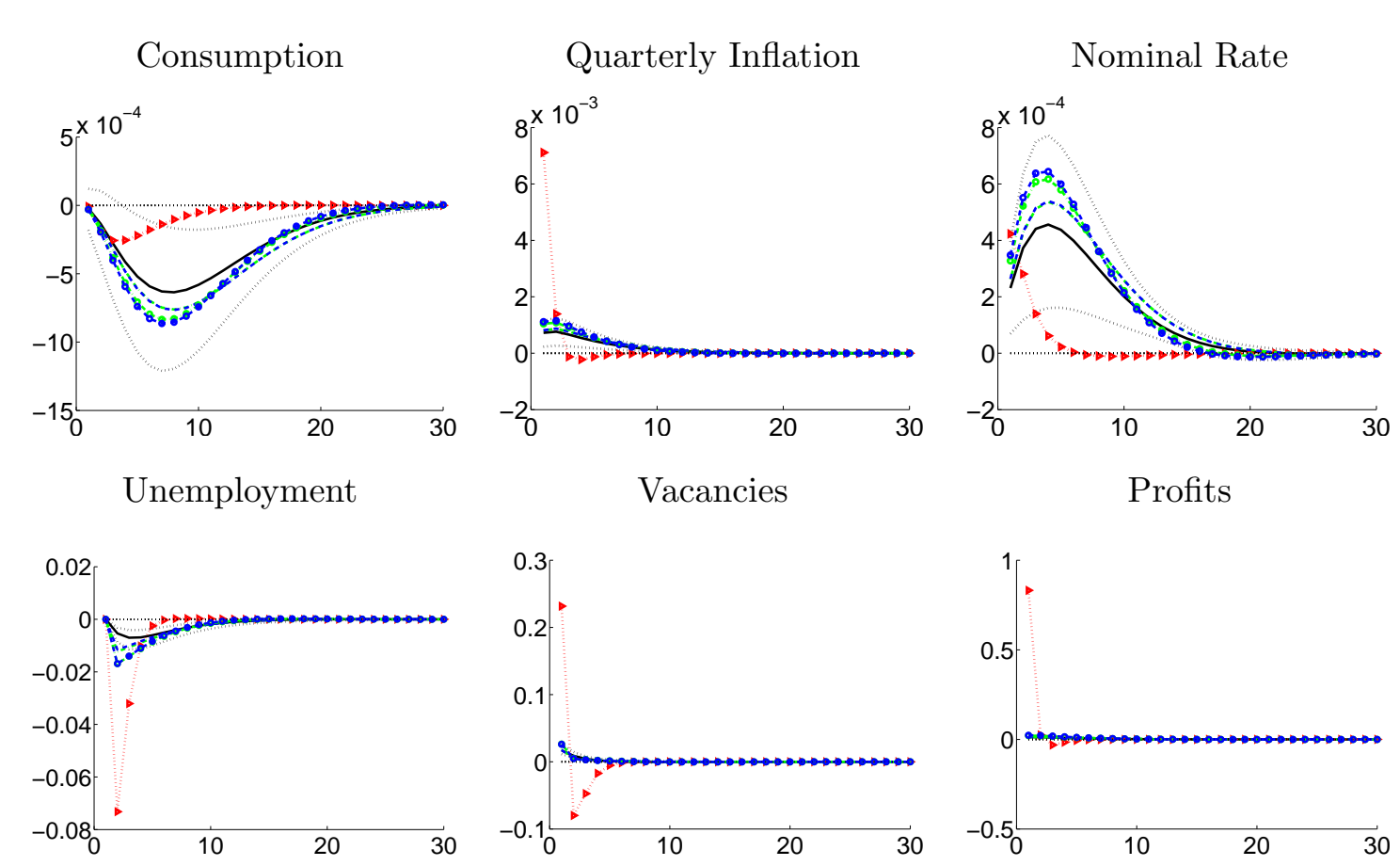

Hours

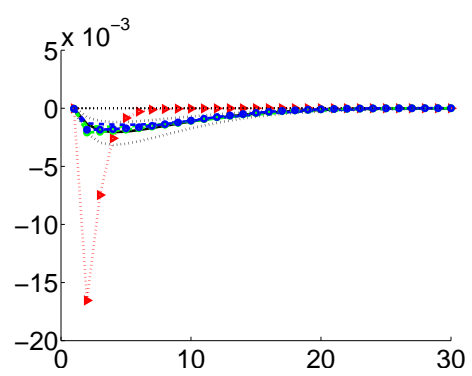

Marginal Cost

Real Wage Rate
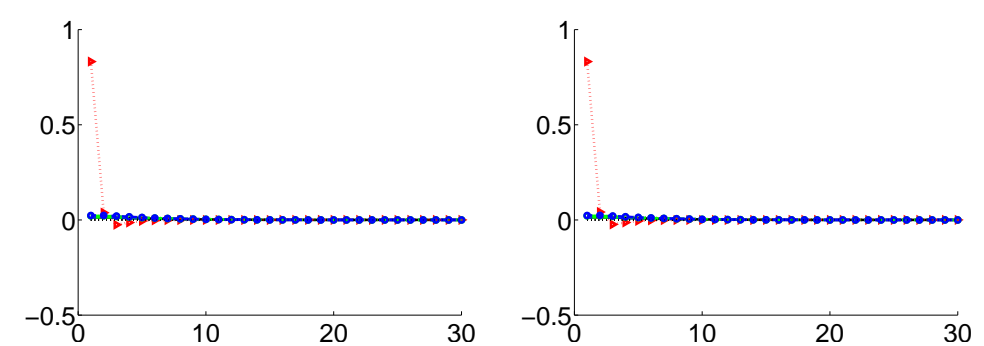

Notes: The figures show percentage responses (1 in the plots corresponds to $1 \%$ ) of endogenous variables to a one percent increase in the disutility of hours worked shock. The black solid line marks the estimated model (at the posterior mode). Black dotted lines mark 95\% confidence intervals (using 100.000 draws from the posterior distribution). The red line marked by triangles shows the case of no wage rigidity. The remaining blue and green lines correspond to the counterfactual flexible labor market experiments described in more detail in Appendix E. Nb: an increase of unemployment of 1 in the plot means that the unemployment rate increases by $1 \%$, say from 0.15 to 0.1515 ; not by one percentage point! 


\section{Conclusions}

In this paper we estimate a small-scale DSGE model with search and matching frictions for Germany by Bayesian full-information techniques. To account for wage and inflation persistence we model quadratic wage adjustment costs in the search and matching framework. Using a set of structural shocks including a labor market specific shock we are able to present evidence on the relative importance of specific disturbances. Furthermore we assess the role of labor market rigidities by counterfactual policy simulations.

Our results can be summarized as follows. First, we find that the structure of the labor market matters substantially for the overall behavior of the model and the transmission of monetary policy on inflation in particular. The specific settings of the labor market, as for example the degree of wage inertia or the efficiency of the matching process, are found to have a notable impact on the dynamic properties of the model. The impact of the labor market is stronger for inflation than for aggregate demand. Specifically, we find that the degree of wage rigidity is positively correlated with inflation persistence. Furthermore we find that a higher degree of wage rigidity amplifies real adjustment in the labor market and leads to more fluctuations in employment. The degree of rigidity in the labor market has an impact on the ability of an economy to adjust to economic shocks. If the frictions associated with finding a new job are sizeable, our results show that the effects of shocks on inflation last longer.

Second, the realization of labor market shocks has an impact on the labor market itself but a limited impact on the other blocks of the model. The limited pass-through of labor market shocks to other sectors can be related to several specific modelling issues. The current model abstracts from modelling investment and capital. This implies that labor market shocks do not have a longer term impact via the the dynamic interaction with capital adjustments. As it is the case in the more general class of New Keynesian DSGE models our model has the property that production is determined by demand in the short run. Under the assumption of perfect consumption insurance, unemployment 
spells do not have an impact on the income of the individuals and are therefore not affecting aggregate demand. Furthermore the rigidities in the labor market imply that adjustments in the number of employed workers can be implemented only after a time lag of one period. This implies that hours worked per employee have to absorb the bulk of adjustment implying an overstated volatility of hours and a limited impact of labor market shocks on inflation.

Third, to the extent a central bank's task is to keep inflation low and stable policy makers need to have a good understanding of the structure of the labor-market. The realization of labor market specific shocks, however, does not contain important information for the conduct of monetary policy. 


\section{References}

Abel, A. (1990): "Asset Prices under Habit Formation and Catching Up with the Joneses," American Economic Review, Papers and Proceedings, 80, 38-42.

Altig, D., L. J. Christiano, M. Eichenbaum, and J. Linde (2005): "FirmSpecific Capital, Nominal Rigidities and the Business Cycle," .

Bachmann, R. (2005): "Labour Market Dynamics in Germany: Hirings, Separations, and Job-to-Job Transitions over the Business Cycle," Humboldt University: SFB Discussion Paper 2005-45.

Boldrin, M., L. Christiano, and J. Fisher (2001): "Habit Persistence, Asset Returns and the Business Cycle," American Economic Review, 91(1), 149-166.

Burda, M., And C. Wyplosz (1994): "Gross Worker and Job Flows in Europe," European Economic Review, 38(6), 1287-1315.

Calvo, G. (1983): "Staggered Prices in a Utility Maximizing Framework," Journal of Monetary Economics, 12, 383-398.

Campbell, J., A. Lo, and C. MacKinlay (1997): The Econometrics of Financial Markets. Princeton University Press, Princeton.

Christiano, L. J., M. Eichenbaum, and C. Evans (2005): "Nominal Rigiditiesn and the Dynamic Effects of a Shock to Monetary Policy," Journal of Political Economy.

Christoffel, K., and T. Linzert (2005): "The Role of Real Wage Rigidity and Labor Market Frictions for Inflation and Unemployment Dynamics," mimeo.

Clarida, R., J. Gali, and M. Gertler (1998): "Monetary Policy Rules in Practice. Some International Evidence," European Economic Review, 42(6), 1033-1067.

del Negro, M., F. Schorfheide, F. Smets, and R. Wouters (2004): "On the Fit and Forecasting Performance of New Keynesian Models," Federal Reserve Bank of Atlanta Working Paper 2004-37.

Eichenbaum, M., and J. Fisher (2003): "Evaluating the Calvo Model of Sticky Prices," Federal Reserve Bank of Chicago, Working Paper 2003-23.

Francis, N., And V. A. Ramey (2002): "Is the Technology-Driven Real Business Cycle Hypothesis Dead? Shocks and Aggregate Fluctuations Revisited," NBER Working Paper No. 8726.

Funrer, J. (2000): "Habit Formation in Consumption and Its Implications for Monetary-Policy Models," American Economic Review, 90(3), 367-390.

Gali, J. (1999): "Technology, Employment and the Business Cycle: Do Technology Shocks Explain Aggregate Fluctuations?," American Economic Review, 89(1), 249271. 
Gali, J., M. Gertler, and D. López-SAlido (2001): "European Inflation Dynamics," European Economic Review, 45.

HAll, R. (2005): "Employment Fluctuations with Equilibrium Wage Stickiness," American Economic Review, 95(1), 1.

Hoffmann, J., and J.-R. Kurz-Kim (2004): "Consumer Price Adjustment Under the Microscope: Germany in a Period of Low Inflation," Unpublished Manuscript; proceeding of the "Inflation Persistence Network".

Lubik, T., And F. Schorfheide (2005): "A Bayesian Look at New Open Economy Models," .

Mortensen, D., and C. Pissarides (1994): "Job Creation and Job Destruction in the Theory of Unemployment," Review of Economic Studies, 61, 397-415.

Schorfheide, F. (2000): "Loss Function-based Evaluation of DSGE Models," Journal of Applied Econometrics, 15(6), 645-670.

Shimer, R. (2005): "The Cyclical Behavior of Equilibrium Unemployment, Vacancies, and Wages: Evidence and Theory," American Economic Review, 95(1), 25-49.

Smets, F., And R. Wouters (2003): "An Estimated Stochastic Dynamic General Equilibrium Model of the Euro Area," Journal of European Economic Association, 1(5), 1123-75.

TAYloR, J. B. (1993): "Discretion Versus Policy Rules in Practice," CarnegieRochester Conference Series on Public Policy, 39, 195-214.

Trigari, A. (2004): "Equilibrium Unemployment, Job Flows and Inflation Dynamics," ECB Working Paper, 304,--

Woodford, M. (2003): Interest and Prices: Foundations of a Theory of Monetary Policy. Princeton University Press, Princeton. 


\section{A Linearized Model}

\section{A.1 Equations independent of the RTM specification}

$$
\begin{gathered}
\widehat{\lambda}_{t}=\widehat{r}_{t}^{r e a l}+E_{t} \widehat{\lambda}_{t+1} . \\
\widehat{\lambda}_{t}=\epsilon_{t}^{\text {pref }}-\frac{\sigma}{1-h_{c}}\left\{\widehat{c}_{t}-h_{c} \widehat{c}_{t-1}\right\} .
\end{gathered}
$$

This implies the Euler equation

$$
\begin{aligned}
& \widehat{c}_{t}=\frac{h_{c}}{1+h_{c}} \widehat{c}_{t-1}+\frac{1}{1+h_{c}} E_{t} \widehat{c}_{t+1}-\frac{1-h_{c}}{\sigma\left(1+h_{c}\right)} \widehat{r}_{t}^{\text {real }}+\frac{1-h_{c}}{\sigma\left(1+h_{c}\right)}\left(\widehat{\epsilon}_{t}^{\text {pref }}-E_{t} \boldsymbol{\epsilon}_{t+1}^{\text {pref }}\right) . \\
& \widehat{r}_{t}^{\text {real }}=\widehat{i}_{t}-E_{t} \widehat{\pi}_{t+1} \text {. } \\
& \widehat{y}_{t}=\widehat{n}_{t}+\widehat{z}_{t}+\alpha \widehat{h}_{t} \text {. } \\
& \widehat{m}_{t}=\bar{\sigma}_{2} \widehat{u}_{t}+\left(1-\bar{\sigma}_{2}\right) \widehat{v}_{t} . \\
& \widehat{s}_{t}=\widehat{m}_{t}-\widehat{u}_{t} . \\
& \widehat{q}_{t}=\widehat{m}_{t}-\widehat{v}_{t} . \\
& \widehat{\theta}_{t}=\widehat{s}_{t}-\widehat{q}_{t}=\widehat{v}_{t}-\widehat{u}_{t} \\
& \widehat{n}_{t}=(1-\rho) \widehat{n}_{t-1}+\rho \widehat{m}_{t-1} \text {. } \\
& \widehat{u}_{t}=-(1-\rho) \frac{\bar{n}}{\bar{u}} \widehat{n}_{t} \text {. } \\
& \widehat{q}_{t}=\widehat{\kappa}_{t}-(1-\beta(1-\rho)) E_{t} \widehat{\lambda}_{t+1}+\frac{\rho}{1-\rho} E_{t} \widehat{\rho}_{t+1}-(1-\beta(1-\rho)) E_{t} \widehat{\psi}_{t+1}+\beta(1-\rho) E_{t}\left\{\widehat{q}_{t+1}-\widehat{\kappa}_{t+1}\right\} . \\
& \widehat{\psi}_{t}=\frac{1}{\bar{\psi}}\left\{\bar{x} \bar{z}^{\alpha}\left\{\widehat{x}_{t}+\widehat{z}_{t}+\alpha \widehat{h}_{t}\right\}-\bar{w} \bar{h}\left\{\widehat{w}_{t}+\widehat{h}_{t}\right\}\right\} . \\
& \widehat{m p l}_{t}=\widehat{z}_{t}+(\alpha-1) \widehat{h}_{t} . \\
& \widehat{m r s_{t}}=\widehat{\kappa_{h} t}+\phi \widehat{h}_{t}-\widehat{\lambda}_{t} . \\
& \widehat{i}_{t}=\rho \widehat{i}_{t-1}+(1-\rho) \gamma_{\pi}\left(\widehat{\pi}_{t+1 \mid t}-\widehat{\bar{\pi}}_{t}\right)+(1-\rho) \gamma_{y} \widehat{y}_{t} \text {. } \\
& \widehat{\pi}_{t}=\frac{\beta}{1+\beta \gamma} E_{t} \widehat{\pi}_{t+1}+\frac{\gamma}{1+\beta \gamma} \widehat{\pi}_{t-1}+\frac{(1-\varphi)(1-\varphi \beta)}{\varphi(1+\beta \gamma)}\left(\widehat{x}_{t}+\widehat{e}_{t}\right) . \\
& \widehat{e}_{t}=\frac{1}{1-\bar{\epsilon}} \widehat{\epsilon}_{t}^{c p} \text {. }
\end{aligned}
$$




\section{A.2 First-order conditions of bargaining with RTM}

\section{A.2.1 Hours}

$$
\widehat{x}_{t}+\widehat{m p l}_{t}=\widehat{w}_{t} .
$$

implying

$$
\widehat{x}_{t}+\widehat{z}_{t}+(\alpha-1) \widehat{h}_{t}=\widehat{w}_{t}
$$

Note also that for RTM ${ }^{29}$

$$
\widehat{\psi}_{t}=\widehat{w}_{t}+\widehat{h}_{t} .
$$

\section{A.2.2 Real wage rate}

$$
\begin{aligned}
& \widehat{w}_{t}=\xi_{1} \widehat{\chi}_{t}+\gamma_{1} \widehat{m r s} t+\gamma_{2}\left(\widehat{\kappa}_{t}+\widehat{\theta}_{t}-\widehat{\lambda}_{t}-\widehat{h}_{t}\right)-\gamma_{3} \widehat{h}_{t}-\xi_{2} E_{t} \widehat{\chi}_{t+1} . \\
& \xi_{1}=\frac{1}{1-\frac{\bar{\chi}}{\alpha}}\left\{\bar{\chi}\left\{\frac{1}{\alpha}+\frac{\bar{\kappa} \bar{\theta}}{\overline{\lambda h} \bar{w}}-\frac{\overline{m r s}}{\bar{w}(1+\phi)}-\frac{\bar{b}}{\bar{h} \bar{w}}\right\}+\frac{\bar{\chi}}{1-\bar{\chi}}\left\{\frac{\bar{\kappa}}{\bar{\lambda} \bar{q} \bar{h} \bar{w}}(1-\bar{s})\right\}\right\} . \\
& \xi_{2}=\frac{1}{1-\frac{\bar{\chi}}{\alpha}}\left\{(1-\bar{s}) \frac{\bar{\kappa}}{\bar{\lambda} \bar{q} \bar{h} \bar{w}} \frac{\bar{\chi}}{1-\bar{\chi}}\right\} \text {. } \\
& \gamma_{1}=\frac{1}{1-\frac{\bar{\chi}}{\alpha}}\left\{\frac{\overline{m r s}}{\bar{w}(1+\phi)}(1-\bar{\chi})\right\} \text {. } \\
& \gamma_{2}=\frac{1}{1-\frac{\bar{\chi}}{\alpha}}\left\{\bar{\chi} \frac{\bar{\kappa} \bar{\theta}}{\overline{\lambda h} \bar{w}}\right\} \text {. } \\
& \gamma_{3}=\frac{1}{1-\frac{\bar{\chi}}{\alpha}}\left\{(1-\bar{\chi}) \frac{\bar{b}}{\bar{h} \bar{w}}\right\} \text {. } \\
& \widehat{\chi}_{t}=(1-\bar{\chi})\left\{\widehat{\delta}_{t}^{w, w}-\widehat{\delta}_{t}^{f, w}\right\} \text {. } \\
& \widehat{\delta}_{t}^{w, w}=\widehat{h}_{t}-\frac{\frac{\overline{m r s}}{\bar{w}}}{\alpha-\frac{\overline{m r s}}{\bar{w}}}\left(\widehat{m r s}_{t}-\widehat{w}_{t}\right) \text {. } \\
& \widehat{\delta}_{t}^{f, w}=\widehat{h}_{t}+\frac{\bar{w}}{\bar{h}} \phi_{L}\left[\left(\widehat{w}_{t}-\widehat{w}_{t-1}\right)-\beta(1-\rho)\left(\widehat{w}_{t+1 \mid t}-\widehat{w}_{t}\right)\right] .
\end{aligned}
$$

We define $\phi_{L}^{\text {new }}:=\frac{\bar{w}}{\bar{h}} \phi_{L} / 1000$.

${ }^{29}$ Using the definition of profits and the FOC for hours,

$$
\psi_{t}+\text { adj. costs }=x_{t} z_{t} h_{t}^{\alpha}-w_{t} h_{t}=x_{t} m p l_{t} \frac{h_{t}}{\alpha}-w_{t} h_{t}=w_{t} h_{t}\left[\frac{1-\alpha}{\alpha}\right] .
$$

Since adjustment costs have no first-order effect on profits, in equilibrium profits are tightly linked to the total wage bill. 


\section{B Data}

\section{B.1 Source of Data}

Table 6: Data Description and Sources

Price level

Nominal interest rate

Vacancies

Consumption

Labour force

Employment

Wages

Hours
Consumer price index, CPI all items,

base year 2000, own seasonal adjustment

Source: OECD

3-month money market interest rate, interbank market

Frankfurt, monthly average, $\%$ p.a.

Source: OECD

Unfilled job vacancies, seasonally adjusted,

Quantum (non-additive or stock figures), in 1000 persons Source: OECD

Private final consumption expenditure, GDP by expenditure, quarterly levels, 1995 prices, seasonally adjusted Source: OECD

Total labour force, in 1000 persons, own seasonal adjustment Source: OECD

Civilian employment (survey), seasonally adjusted,

all persons, all ages, in 1000 persons

Source: OECD

Hourly earnings: manufacturing, index publication base,

base year 2000, seasonally adjusted

Source: OECD

Hours of work total industry, excluding construction, seasonally adjusted

Source: Eurostat 


\section{B.2 Plots of the Raw Data}

Figure 8: Plots of the Raw Data
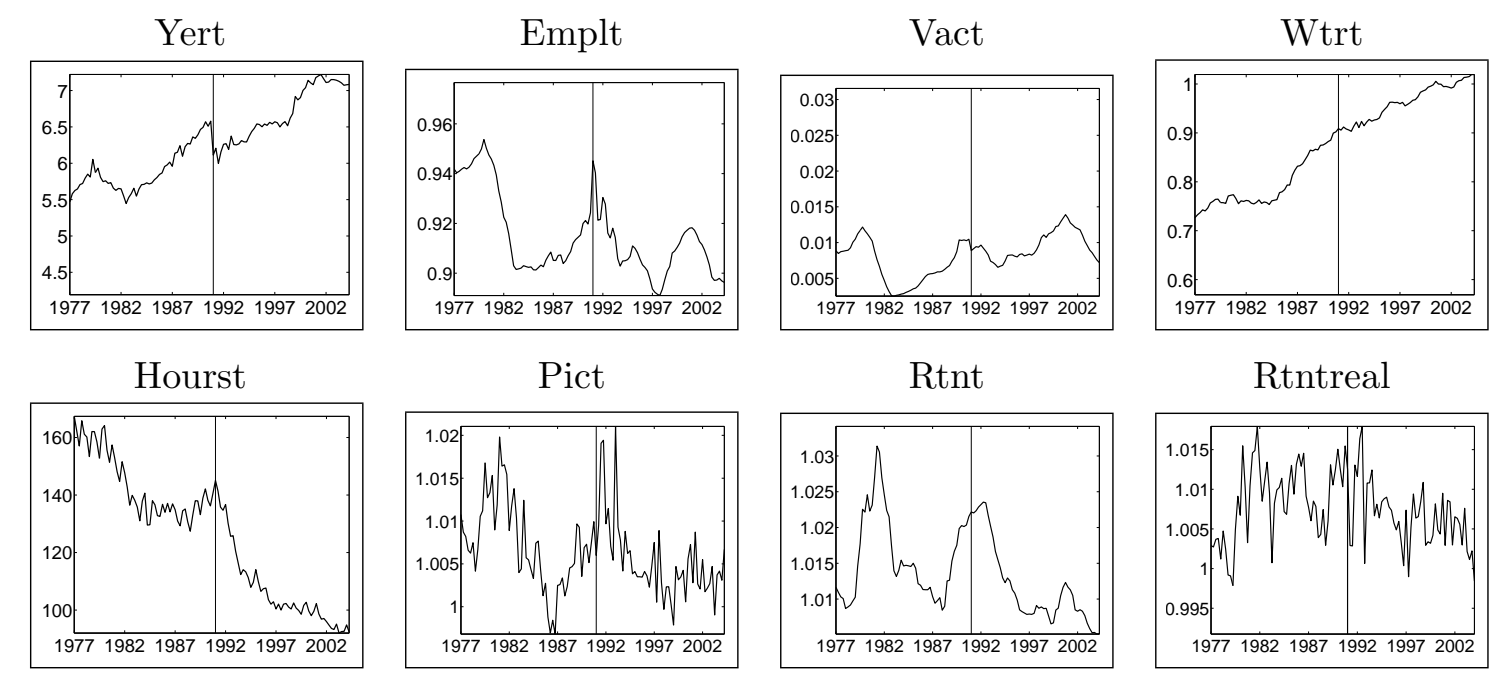

Notes: Yert: seasonally adjusted real private consumption (1995 prices)/labour force, Emplt: Civilian Employment seasonally adjusted/Labour force, Vact: Vacancies seasonally adjusted/labour force, Wtrt: Index of hourly earnings seasonally adjusted (year 2000 '='100)/CPI(year 2000 '='1), Hourst: hours of work total industry, excluding construction, Pict: gross CPI inflation rate quarter on quarter, seasonally adjusted, Rtnt: gross nominal quarterly 3-month rate, Rtntreal: ex post gross real interest rate. 


\section{B.3 Plots of the Detrended Data}

Figure 9: Plots of the Detrended and Demeaned Series
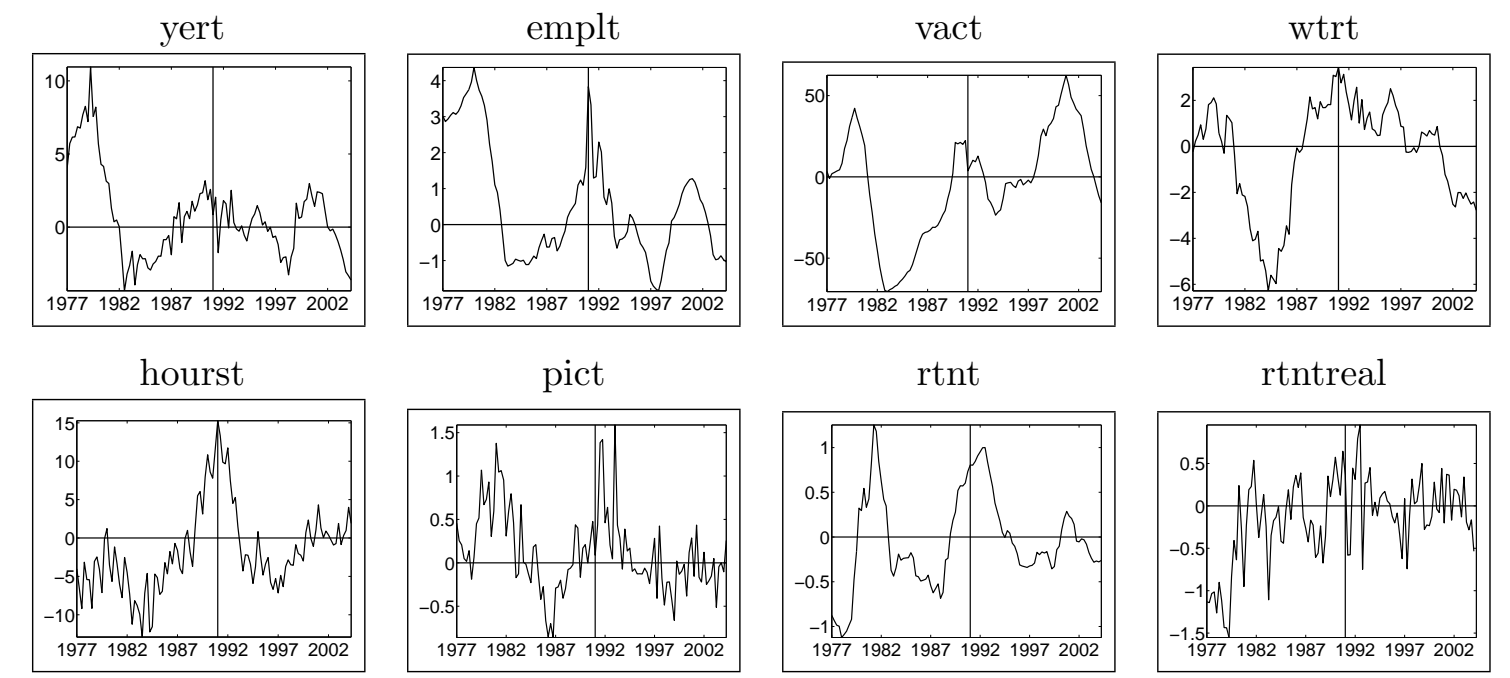

Notes: Same as in Figure 8 as log-deviations from a respective trend (see below). The data span 1977:1 to 2004:2. All series are multiplied by 100 in order to give percentage deviations from steady state. The trends and constants have been computed using data from 1984:3 to 2004:2. Log consumption was regressed on a constant, a reunification dummy and a linear trend. Log employment rates were demeaned and detrended. Vacancies (in levels) were computed as vact $:=($ Vact - mean $($ Vact $)) /$ mean $($ Vact $)$ and hence not detrended. Log real wage rates were regressed on a constant and a linear trend. Log hours worked were demeaned and detrended. Inflation rates were demeaned and detrended. The interest rate was demeaned and detrended. 


\section{Persistence and Cross-correlations in the Data}

Table 7: Standard Deviation and Persistence

\begin{tabular}{lccrrrr}
\hline Names & std & sum1 & sum2 & sum3 & sum4 & sum5 \\
\hline \hline$\widehat{r}_{t}$ & 0.4368 & 0.9734 & 0.9606 & 0.9551 & 0.9398 & 0.9376 \\
$\widehat{y}_{t}$ & 1.7292 & 0.7999 & 0.8605 & 0.8328 & 0.8329 & 0.7819 \\
$\widehat{v}_{t}$ & 30.0150 & 0.9561 & 0.9598 & 0.9565 & 0.9510 & 0.9520 \\
$\widehat{n}_{t}$ & 1.0887 & 0.9062 & 0.8797 & 0.9347 & 0.9035 & 0.8753 \\
$\widehat{w}_{t}$ & 2.2260 & 0.9296 & 0.9200 & 0.9065 & 0.9249 & 0.9205 \\
$\widehat{h}_{t}$ & 5.3275 & 0.8593 & 0.8867 & 0.9139 & 0.9139 & 0.8944 \\
$\widehat{\pi}_{t}^{a n n}$ & 1.3228 & 0.9335 & 0.9176 & 0.9114 & 0.8963 & 0.9246 \\
\hline
\end{tabular}

Notes: sum1 is the first-order autoregression coefficient (OLS), sum2 is the sum of the first two autoregression coefficients (OLS) and so forth. Standard is the standard deviation of the time series. The data are 1984:3 to 2004:2.

Table 8: Cross-correlations

\begin{tabular}{lccccccc}
\hline Names & $\widehat{r}_{t}$ & $\widehat{y}_{t}$ & $\widehat{v}_{t}$ & $\widehat{n}_{t}$ & $\widehat{w}_{t}$ & $\widehat{h}_{t}$ & $\widehat{\pi}_{t}^{\text {ann }}$ \\
\hline \hline$\widehat{r}_{t}$ & 1.0000 & 0.4755 & 0.3578 & 0.7658 & 0.4866 & 0.7403 & 0.8506 \\
$\widehat{y}_{t}$ &. & 1.0000 & 0.5185 & 0.7146 & 0.5948 & 0.4937 & 0.2374 \\
$\widehat{v}_{t}$ &. &. & 1.0000 & 0.4891 & 0.3395 & 0.3863 & 0.1383 \\
$\widehat{n}_{t}$ &. &. &. & 1.0000 & 0.4772 & 0.7972 & 0.4833 \\
$\widehat{w}_{t}$ &. &. &. &. & 1.0000 & 0.4748 & 0.3676 \\
$\widehat{h}_{t}$ &. &. &. &. &. & 1.0000 & 0.4772 \\
$\widehat{\pi}_{t}^{a n n}$ &. &. &. &. &. &. & 1.0000 \\
\hline
\end{tabular}

Notes: Cross-correlations of the data computed from 1984:3 to 2004:2. 


\section{Further Estimation Statistics for the Parameters}

Table 9: Summary Statistics for Estimated Parameters

\begin{tabular}{|c|c|c|c|c|c|c|c|c|}
\hline \multirow[t]{2}{*}{ Parameter } & \multicolumn{3}{|l|}{ prior } & \multicolumn{5}{|c|}{ posterior } \\
\hline & mean & std & distr. & mean & median & mode & \multicolumn{2}{|c|}{$95 \%$ conf. interval } \\
\hline \multicolumn{9}{|c|}{ Parameters of Structural Model } \\
\hline$\rho_{m}$ & 0.750 & 0.0500 & norm & 0.80 & 0.80 & 0.78 & 0.73 & 0.86 \\
\hline$\gamma_{\pi}$ & 1.500 & 0.3000 & norm & 1.46 & 1.45 & 1.40 & 1.01 & 1.92 \\
\hline$\gamma_{y}$ & 0.125 & 0.3000 & norm & 0.21 & 0.21 & 0.19 & 0.10 & 0.34 \\
\hline$h_{c}$ & 0.850 & 0.0500 & norm & 0.83 & 0.84 & 0.83 & 0.77 & 0.89 \\
\hline$\varphi$ & 0.900 & 0.0500 & norm & 0.93 & 0.93 & 0.92 & 0.90 & 0.95 \\
\hline$\gamma_{p}$ & 0.300 & 0.1000 & norm & 0.27 & 0.27 & 0.26 & 0.14 & 0.41 \\
\hline$\sigma_{2}$ & 0.400 & 0.0500 & norm & 0.33 & 0.33 & 0.31 & 0.23 & 0.43 \\
\hline$\phi_{L}^{n e w}$ & 0.250 & 0.1000 & norm & 0.37 & 0.37 & 0.36 & 0.27 & 0.47 \\
\hline \multicolumn{9}{|c|}{ Serial Correlation of Shocks } \\
\hline$\rho_{\bar{\pi}}$ & 0.300 & 0.2000 & norm & 0.35 & 0.36 & 0.36 & 0.17 & 0.55 \\
\hline$\rho_{\kappa}$ & 0.700 & 0.1000 & norm & 0.60 & 0.61 & 0.60 & 0.49 & 0.72 \\
\hline$\rho_{z}$ & 0.900 & 0.0250 & norm & 0.93 & 0.93 & 0.93 & 0.88 & 0.98 \\
\hline$\rho_{\kappa_{h}}$ & 0.300 & 0.1000 & norm & 0.21 & 0.21 & 0.20 & 0.05 & 0.36 \\
\hline \multicolumn{9}{|c|}{ Standard Deviation of Innovations } \\
\hline$\mu^{\bar{\pi}}$ & 0.007 & Inf & invg & 0.003 & 0.003 & 0.003 & 0.002 & 0.004 \\
\hline$\mu^{p r e f}$ & 0.100 & Inf & invg & 0.074 & 0.072 & 0.068 & 0.048 & 0.105 \\
\hline$\mu^{z}$ & 0.006 & Inf & invg & 0.004 & 0.005 & 0.004 & 0.002 & 0.007 \\
\hline$\mu^{\operatorname{cost}-p u s h}$ & 0.001 & Inf & invg & 0.003 & 0.003 & 0.003 & 0.002 & 0.004 \\
\hline$\mu^{\kappa}$ & 0.010 & Inf & invg & 0.028 & 0.028 & 0.025 & 0.016 & 0.043 \\
\hline$\mu^{\kappa_{h}}$ & 0.200 & 0.1000 & norm & 0.443 & 0.443 & 0.435 & 0.336 & 0.553 \\
\hline
\end{tabular}

Notes: Parameter estimates using 100.000 draws (after burn in) in the Metropolis-Hastings algorithm. Nota bene: The underlying calibration is such that $\bar{q}=0.7391, \bar{s}=0.4928, \bar{w} \bar{h} / \bar{y}=\alpha=0.72, \bar{\kappa} /(\bar{\lambda} \bar{y})=1.4771$, $b /(\bar{w} \bar{h})=0.5, \bar{u}=0.15$ and $\bar{v}=0.1$. 


\section{E Flexible Labor Market Experiments}

The impulse responses (Figures 2 to 7 ) show the estimated benchmark model along with counterfactual scenarios that are meant to illustrate the behaviour of the economy if the labor market were more flexible. In detail, they are constructed as follows:

1. The black solid line marks the impulse response when the estimated parameters (at the posterior mode) are used along with the baseline calibration.

2. The red dotted line marked by triangles shows the impulse responses when the estimated parameters of the model are used but for eliminating wage rigidity. We set the latter to a very small value, $\phi_{L}^{\text {new }}=1 . e-6$. This case shows how import the wage rigidity friction is. Clearly, the steady state relative to the estimated model is not changed by altering $\phi_{L}^{\text {new }}$.

3. The green dash-dotted line without markers shows the response when the estimated parameters of the model are used but the labor market is less rigid in the following sense: We assume that all workers almost immediately find a job in steady state (not necessarily outside of steady state) - this means there is an abundance of firms in the market. We set $\bar{S} \approx 1$ and $\bar{Q} \approx 0$.

- Clearly, this changes the steady state of the model.

- In order to achieve these changes, vacancy posting costs need to be negligible, $\kappa \approx 0 . \sigma_{m}$ needs to be adjusted to guarantee well defined probability measures in steady state.

- We maintain the assumption that $\frac{\overline{m r s}}{\bar{w}}=1$ and that $\bar{h}=1 / 3$. These assumptions are satisfied by means of a change in $\kappa_{h}$ and $b$ relative to the estimated model.

- This leads to $\frac{b}{w h}=0.1495$ instead of 0.5. Note that for each worker, unemployment becomes less costly (as he is sure to find a job next period), the replacement rate therefore needs to fall.

- With $\bar{S} \approx 1$, there is full employment prior to production, so $\bar{U}=\rho$, which is another change to the steady state.

4. The blue dashed line without markers is the same as in 3 . but that we in addition assume $\rho=0.07$. This implies

- $\frac{b}{w h}=0.0509$ instead of 0.5 .

5. The green dash-dotted line marked by circles is the same as in 3 . but for the fact that we let only $\sigma_{m}$ (to achieve a well defined probability measure) and $\kappa$ change, keeping benefits, $b$, and $\kappa_{h}$ at the level as in the estimated version.

- This leads to the steady state not being efficient anymore $\frac{\overline{m r s}}{\bar{w}}=0.9042$.

- $\bar{u}=0.08$ 
- $\bar{h}=0.3279$

- $\frac{b}{w h}=0.5080$

6. The blue dashed line marked by circles is the same as in 5 . but for the fact that we also assume $\rho=0.07$.

- This leads to the steady state not being efficient anymore $\frac{\overline{m r s}}{\bar{w}}=0.8914$.

- $\bar{u}=0.07$

- $\bar{h}=0.3272$

- $\frac{b}{\bar{w} \bar{h}}=0.5090$ 


\section{F Nominal Wage Adjustment Costs}

In this section, we analyze the dynamics of the estimated model when we assume that adjusting nominal wages causes costs - not the adjustment of the real wage rate. That is, instead of (18) we let profits be characterized by

$$
\psi_{t}(j):=x_{t} y_{t}^{I}(j)-w_{t}(j) h_{t}(j)-\frac{1}{2} \phi_{L}\left(\frac{w_{t}(j)}{w_{t-1}(j)} \frac{\Pi_{t}}{\bar{\Pi}}-1\right)^{2},
$$

Overall, the behaviour of the economy is very similar to the economy under real wage adjustment costs and so are the posterior mode parameter estimates. The only difference appears in the response of the economy to a cost-push shock, which we display for that reason. 
Figure 10: Impulse Responses to 1\% Price-markup Shock.

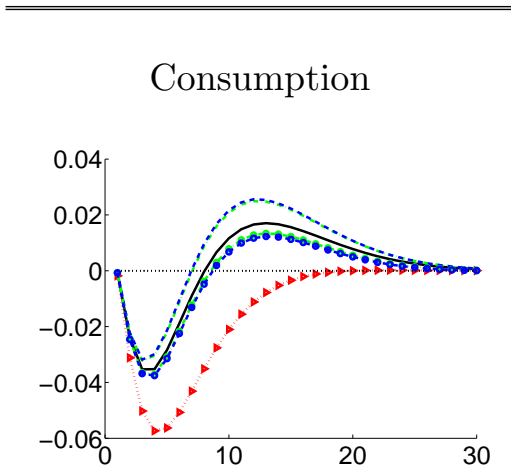

Unemployment

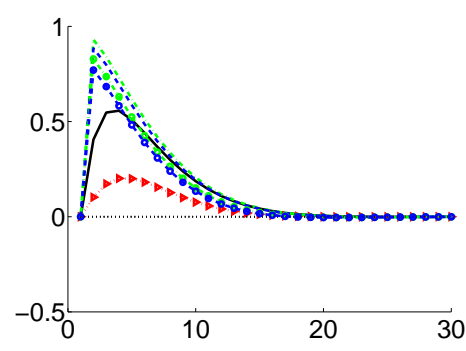

Hours

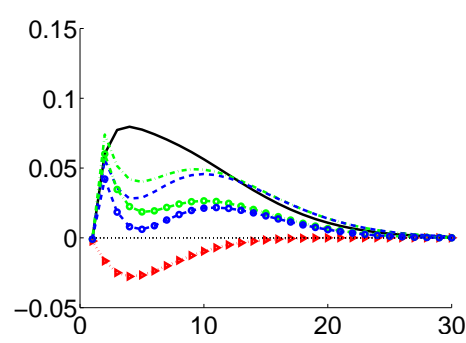

Quarterly Inflation

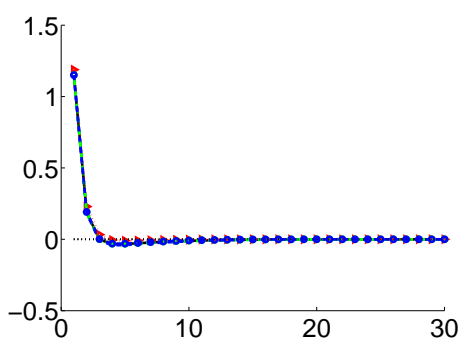

Vacancies
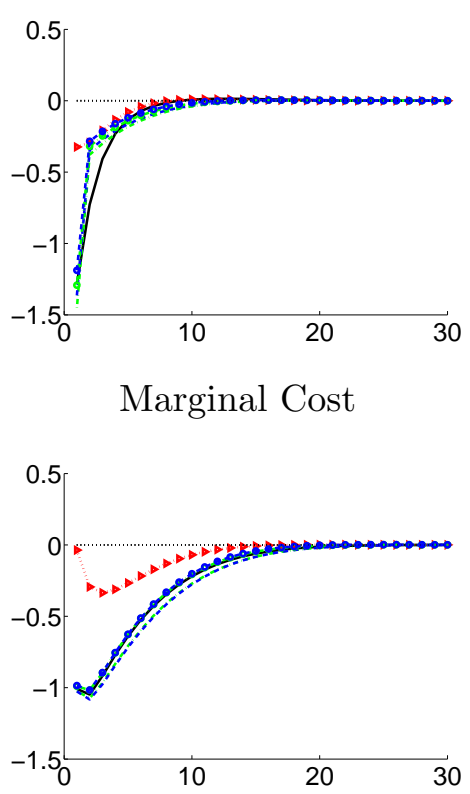

Nominal Rate

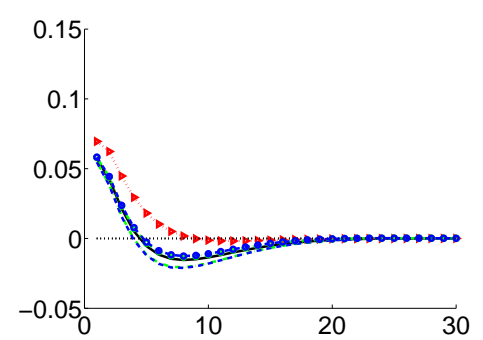

Profits
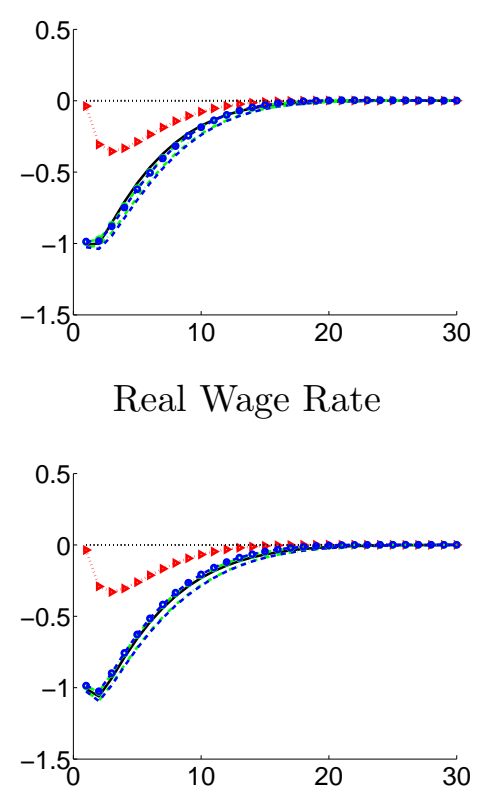

Notes: The figures show percentage responses (1 in the plots corresponds to 1\%) of endogenous variables to a one percent price-markup shock under nominal wage adjustment costs. The black solid line marks the estimated model (at the posterior mode). The red line marked by triangles shows the case of no wage rigidity. The remaining blue and green lines correspond to the counterfactual flexible labor market experiments described in more detail in Appendix E. Nb: an increase of unemployment of 1 in the plot means that the unemployment rate increases by $1 \%$, say from 0.15 to 0.1515 ; not by one percentage point! 


\section{G Calvo Wage Rigidity}

We also experimented with Calvo type real wage rigidities instead of the quadratic adjustment costs. ${ }^{30}$ Let $\gamma$ be the probability that a firm-worker pair cannot update its wage. Instead of the wage equation (33) the Calvo model features the following (mostly auxiliary) equations. Parameter estimates are very similar to the version with quadratic adjustment costs - we therefore do not report them here. The wage adjustment costs estimated above translate to a Calvo wage stickiness of roughly $\gamma=\frac{1}{2}$ at the posterior mode.

$$
\widehat{G a p 1}_{t}=\frac{1-\beta(1-\rho)(1-s)}{1-\tilde{\beta}} \frac{1}{\frac{\phi}{1+\phi}-\frac{b}{w h}}\left(\widehat{w}_{t-1}^{*}-\widehat{w}_{t-1}\right),
$$

where $\tilde{\beta}=\beta(1-\rho) \gamma$.

$$
\begin{aligned}
\widehat{G a p 1}_{t}= & \frac{1-\beta(1-\rho)(1-s)}{1-\tilde{\beta}} \frac{1}{\frac{\phi}{1+\phi}-\frac{b}{w h}}\left(\widehat{w}_{t-1}-\widehat{w}_{t}^{*}\right) . \\
\widehat{W U}_{t}= & \frac{1-\beta(1-\rho)(1-s)}{\frac{\phi}{1+\phi}-\frac{b}{w h}}\left(\widehat{w}_{t}^{*}+\frac{1}{1+\phi}\left(\widehat{\lambda}_{t}-\widehat{\kappa}_{h, t}\right)\right) \\
+ & \beta(1-\rho)(1-s) E_{t} \widehat{W U}_{t+1} \\
+ & \beta(1-\rho)(1-s)\left(\widehat{\lambda}_{t+1}-\widehat{\lambda}_{t}\right)+\tilde{\beta}(1-s) E_{t} \widehat{G a p 2} \widehat{t}_{t+1} \\
+ & \tilde{\beta} E_{t} \widehat{G a p 1}_{t+1}-\beta(1-\rho) s \widehat{s}_{t} . \\
\widehat{J}_{t}= & \frac{1-\beta(1-\rho)}{\alpha-1}\left(\alpha \widehat{w}_{t}^{*}-\widehat{z}_{t}-\widehat{x}_{t}\right) \\
& +\frac{\tilde{\beta}}{1-\widehat{\beta}}\left(\frac{1-\gamma}{\gamma}+1-\beta(1-\rho)\right)\left(E_{t} \widehat{\lambda}_{t+1}-\widehat{\lambda}_{t}\right) \\
& +\frac{\tilde{\beta}}{\gamma} E_{t} \widehat{J}_{t+1} \\
& +\frac{\tilde{\beta}}{1-\tilde{\beta}}(1-\beta(1-\rho)) \frac{\alpha}{\alpha-1}\left(\widehat{w}_{t}^{*}-E_{t} \widehat{w}_{t+1}^{*}\right) .
\end{aligned}
$$

Wage bargaining FOC

$$
\widehat{W U}_{t}=\widehat{\delta}_{t}^{W}+\widehat{J}_{t}-\widehat{\delta}_{t}^{F}
$$

\footnotetext{
${ }^{30}$ Note that this implies full indexation as is frequently found in the data; see e.g. Christiano, Eichenbaum, and Evans (2005) who find full indexation for US data and Smets and Wouters (2003) who find substantial indexation for euro area data.
} 


$$
\begin{aligned}
\widehat{\delta}_{t}^{W}= & \frac{1-\tilde{\beta}}{(\alpha-1)}\left(1+\frac{\alpha-1-\phi}{\alpha-1}\right) \widehat{w}_{t}^{*} \\
& -\frac{1-\tilde{\beta}}{(\alpha-1)^{2}}(\alpha-1-\phi)\left(\widehat{x}_{t}+\widehat{z}_{t}\right) \\
& +\frac{1-\tilde{\beta}}{\alpha-1}\left(\widehat{\lambda}_{t}-\widehat{\kappa}_{h, t}\right) \\
& +\tilde{\beta}\left(E_{t} \widehat{\lambda}_{t+1}-\widehat{\lambda}_{t}\right) \\
& +\tilde{\beta} \frac{1+(\alpha-1-\phi) /(\alpha-1)}{\alpha-1}\left(\widehat{w}_{t}^{*}-E_{t} \widehat{w}_{t+1}^{*}\right) \\
& +\tilde{\beta} E_{t} \widehat{\delta}_{t+1}^{W} \\
\widehat{\delta}_{t}^{F}=\frac{1-\tilde{\beta}}{\alpha-1}\left(\widehat{w}_{t}^{*}-\widehat{x}_{t}-\widehat{z}_{t}\right)+ & \frac{\tilde{\beta}}{\alpha-1}\left(\widehat{w}_{t}^{*}-E_{t} \widehat{w}_{t+1}^{*}\right)+\tilde{\beta}\left(E_{t} \widehat{\lambda}_{t+1}-\widehat{\lambda}_{t}\right)+\tilde{\beta} E_{t} F \widehat{\delta}_{t+1}^{F} .
\end{aligned}
$$

Aggregate wage

$$
\widehat{w}_{t}=\gamma \widehat{w}_{t-1}+(1-\gamma) \widehat{w}_{t}^{*}
$$

Vacancy Posting

$$
\begin{aligned}
\widehat{J}_{t}= & \frac{1-\beta(1-\rho)}{\alpha-1}\left(\alpha \widehat{w}_{t}^{*}-\widehat{z}_{t}-\widehat{x}_{t}\right) \\
& +(1-\rho) \beta\left(\widehat{\kappa}_{t}-\widehat{\lambda}_{t}-\widehat{q}_{t}\right) \\
& +\frac{\tilde{\beta}}{1-\tilde{\beta}}(1-\beta(1-\rho)) \frac{\alpha}{\alpha-1}\left(\widehat{w}_{t}^{*}-\widehat{w}_{t}\right) .
\end{aligned}
$$

